\title{
Intermediate Filaments and the Plasma Membrane
}

\section{Jonathan C.R. Jones, ${ }^{1}$ Chen Yuan Kam, ${ }^{2}$ Robert M. Harmon, ${ }^{2}$ Alexandra V. Woychek, ${ }^{1}$ Susan B. Hopkinson, ${ }^{1}$ and Kathleen J. Green ${ }^{2}$}

\footnotetext{
${ }^{1}$ The School of Molecular Biosciences, Washington State University, Pullman, Washington 99164

${ }^{2}$ Departments of Dermatology and Pathology, Feinberg School of Medicine, Northwestern University, Chicago, Illinois 60611

Correspondence: jcr.jones@vetmed.wsu.edu
}

\section{SUMMARY}

A variety of intermediate filament (IF) types show intricate association with plasma membrane proteins, including receptors and adhesion molecules. The molecular basis of linkage of IFs to desmosomes at sites of cell-cell interaction and hemidesmosomes at sites of cell-matrix adhesion has been elucidated and involves IF-associated proteins. However, IFs also interact with focal adhesions and cell-surface molecules, including dystroglycan. Through such membrane interactions, it is well accepted that IFs play important roles in the establishment and maintenance of tissue integrity. However, by organizing cell-surface complexes, IFs likely regulate, albeit indirectly, signaling pathways that are key to tissue homeostasis and repair.

\section{Outline}

1 Introduction

2 The desmosome

3 IF-desmosome anchorage: Tissue integrity

4 Nondesmosomal IF membrane complexes

5 The hemidesmosome
6 IFs and FAs

7 Interactions between IFs and dystroglycan in muscle, nerve, and epithelial cells

8 Conclusion

References 
J.C.R. Jones et al.

\section{INTRODUCTION}

Compared with other biopolymers, intermediate filaments (IFs) possess an abundance of both linear strength and elasticity and account for the contribution made by IFs to the integrity of individual cells (Herrmann et al. 2009; Chung et al. 2013). Interestingly, IF appearance and diversification parallel metazoan evolution (Wickstead and Gull 2011). Moreover, as we will discuss, IFs contribute to the development of multicellularity, tissue morphogenesis, and integrity by stabilizing intercellular and cell-matrix adhesions.

Here, we review the interaction between IFs and sites of cell-cell and cell-matrix contact. Desmosomes and hemidesmosomes (HDs) represent the best-understood protein complexes capable of integrating IFs with these sites (see reviews that detail the structure and functions of these crucial adhesions: Jones et al. 1998; Borradori and Sonnenberg 1999; Garrod and Chidgey 2008; de Pereda et al. 2009; Harmon and Green 2013; Kowalczyk and Green 2013). Here, we will focus on the molecular underpinnings of IF-desmosome and IF-HD interactions, but, in addition, will summarize recent evidence for IF interactions with focal adhesions (FAs) and the cell-surface receptor dystroglycan (DG) in muscle and in cultured epithelial cells.

\section{THE DESMOSOME}

In epithelial cells, cardiac myocytes, and other specialized cells, cytoplasmic IFs emanate from the nucleus and terminate at electron-dense structures, called desmosomes, located along the junction of adjacent cells. Biochemically, desmosomes contain members from three distinct protein families - cadherins, catenins, and plakins. As in adherens junctions (AJs), which are sites of actin microfilament attachment, transmembrane, glycosylated cadherins extend into the intercellular space and bind counterparts on an opposing cell, thus, forming adhesive links (Chitaev and Troyanovsky 1997; Getsios et al. 2004; Nie et al. 2011; Lowndes et al. 2014). Desmosomes use two subsets of the cadherin superfamily_-desmogleins (Dsgs) and desmocollins (Dscs) - comprising four and three human isoforms, respectively. Apart from unique Dsg carboxy-terminal extensions, desmosomal cadherins resemble the classic AJ component, E-cadherin (Dusek et al. 2007). Plakoglobin $(\mathrm{Pg})$ and three distinct plakophilins (Pkps) establish interactions with intracellular Dsg and Dsc domains, mirroring those of their respective catenin relatives, $\beta$-catenin and p120 catenin, with classic cadherins (Fig. 1) (Smith and Fuchs 1998; North et al. 1999; Chen et al. 2002). The major IF-associated proteins in desmosomes are plakin family members, exemplified by the cytolinker desmoplakin (DP). DP engages the cadherin-catenin complex by binding Pg and Pkp (Kowalczyk et al. 1997; Kowalczyk et al. 1999; Chen et al. 2002; Bonne et al. 2003).

In contrast to the recruitment of actin by AJs, DP recruits keratin, vimentin, and desmin IFs to the desmosome (Kouklis et al. 1994; Meng et al. 1997; Jefferson et al. 2004). The interaction between DP and IFs can be visualized by immunofluorescence at sites of cell-cell contact (Fig. 2A). The structure of DP consists of a central coiled-coil dimerization domain flanked by amino- and carboxy-terminal domains. The amino-terminal domain of DP contains the characteristic plakin domain comprising tandem spectrinlike repeats, and it is this region that binds the desmosomal armadillo proteins, including Pg, which, in turn, bind the cytoplasmic domain of the desmosomal cadherins. Finally, the carboxy-terminal region consists of three homologous plakin repeat domains (PRDs) and a glycine-serine-arginine-rich region (Fig. 2B). The latter region of DP interacts with IFs, regulates the strength of DP-IF interactions, and has been shown by immunogold electron microscopy (EM) to be localized to the innermost dense plaque (Fig. 2A) (North et al. 1999).

\section{IF-DESMOSOME ANCHORAGE: TISSUE INTEGRITY}

Tissue integrity, particularly in the heart and skin, depends on the intercellular connections forged by desmosomes, as well as their associated IFs. This is highlighted by the crucial role played by the IF cytolinker DP in the regulation and maintenance of the integrity of the sheet of epidermal cells that provides the outer covering of the skin. Conditional knockout of DP in the mouse epidermis indicates that the maintenance of epidermal integrity requires DP, and mechanical stresses to DP-null skin result in intercellular separations (Vasioukhin et al. 2001). Additionally, experiments performed using a truncated form of DP lacking its rod and IF-binding domain (DPNTP) show the role of DP in maintaining cellular integrity as uncoupling IFs from desmosomes severely impact intercellular adhesive strength (Huen et al. 2002). In the heart, the importance of DP in maintaining cellular cohesion has been shown by a novel mouse model in which DP is conditionally knocked out in cardiac cells (Garcia-Gras et al. 2006; Lyon et al. 2014). Along with the cardiomyopathies associated with mutations in DP that will be further discussed below, DP conditional knockout (cKO) hearts display ultrastructural defects, including loss of integrity of intercalated discs (IDs), ruptured desmosomes, and loss of myocyte-myocyte adhesion (Lyon et al. 2014). Additionally, the loss of Pkp-2 in PKP2 ${ }^{-/}$embryos results in the loss of DP from cardiac junctions and the formation of dense granular aggregates comprising DP and desmin and vimentin IFs (Grossmann et al. 2004). Furthermore, DP-IF anchorage 


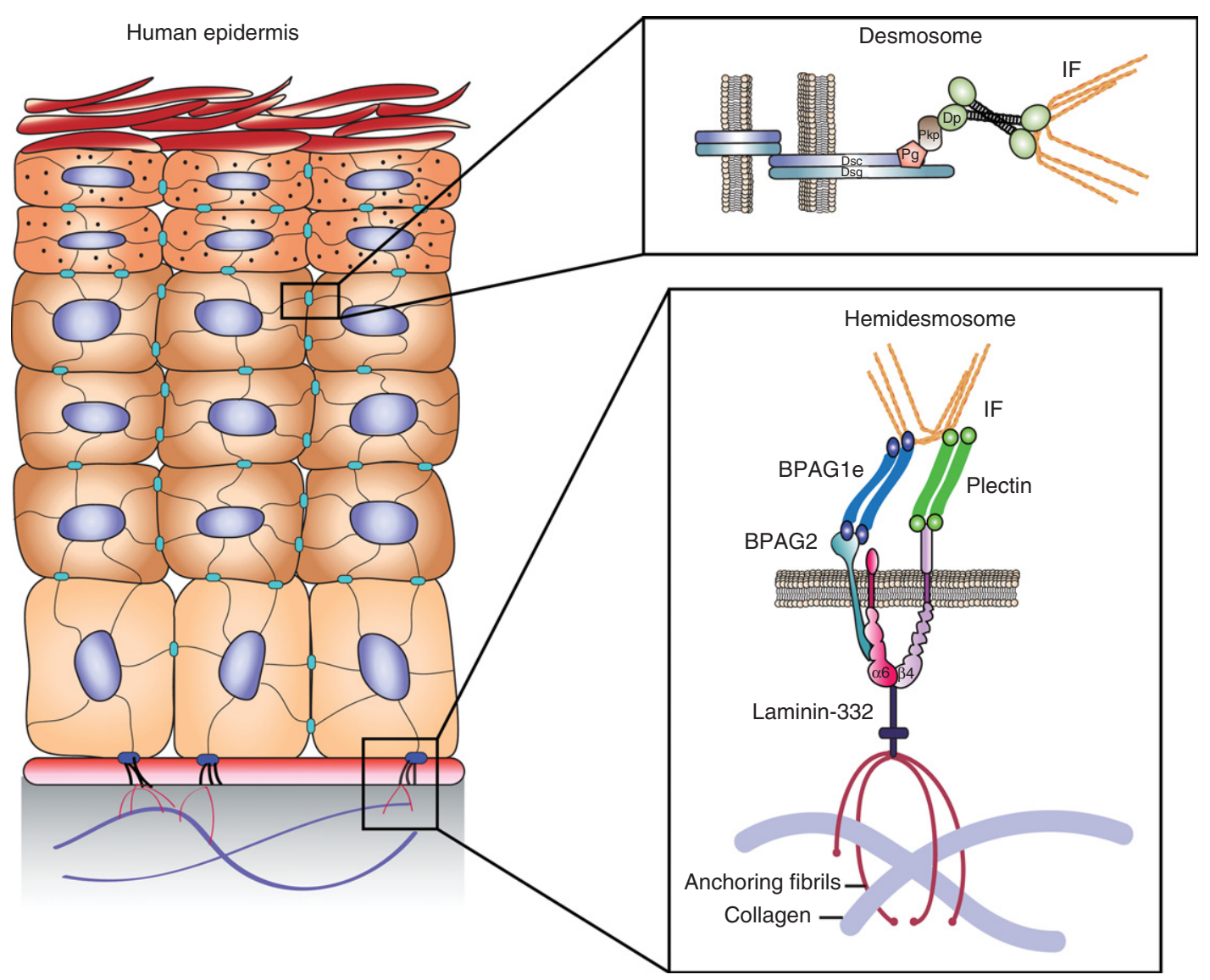

Figure 1. Schematic of intermediate filament (IF) binding complexes of the human epidermis, showing the organization of the protein components of the desmosome junction between neighboring epidermal cells (upper inset) and hemidesmosome junction between a basal epidermal cell and the cell matrix/basement membrane (lower inset). BPAG, bullous pemphigoid antigen; Dsc, desmocollin (a cadherin); Dp, desmoplakin; Dsg, desmoglein (a cadherin); Pg, plakoglobin; Pkp, plakophilin.

has also been implicated in endothelial tissue integrity, as well as in vascular tube formation (Gallicano et al. 2001). In endothelial cells that comprise capillaries and lymph vessels, DP has been shown to be a component of a specialized type of adhering junction known as the "complexus adherens junction," where it links VE-cadherin to the vimentin IF network via the armadillo proteins p0071 or plakoglobin (Schmelz and Franke 1993). The importance of DP in the vasculature is highlighted by the presence of leaky and/or poorly formed capillaries in $\mathrm{DP}^{-/-}$mouse embryos, as well as failure of stable microvascular tube formation in DP-depleted endothelial cell lines (Gallicano et al. 2001).

In humans, genetic, autoimmune, or bacterial-toxinmediated insult directed at the desmosomal complex accounts for diseases of the skin and heart characterized by loss of cell-cell adhesion and aberrant IF-membrane anchorage (Al-Jassar et al. 2013). Mutations in DP, Pg, Pkp, and the desmosomal cadherins result in a spectrum of skin, heart, or a combination of skin and heart defects that range from mild thickening of the skin (keratodermas) to lethal blistering disease and fatal arrhythmias (Petrof et al. 2012; Al-Jassar et al. 2013). One notable example is that of Carvajal syndrome, a genetic disease originally discovered to be caused by a point mutation in DP that produces a premature stop codon leading to a truncated DP protein missing the C domain of the tail region (Norgett et al. 2000). Patients with this disease suffer from striate palmoplantar keratoderma and woolly hair, along with dilated left ventricular cardiomyopathy (Fig. 2C,D). Desmin and keratin mutants also lead to cardiomyopathy and suprabasal epidermal blisters, respectively, suggesting a relationship between desmosomal proteins and the IF network, in which aspects of one depend on the other (Akiyama et al. 2003; Brodehl et al. 2013; for further details, see Jacob et al. 2016).

\subsection{Assembly of IF-desmosomal membrane attachments}

In response to cell-cell contact or increases in extracellular calcium, a complex cascade of events is initiated to inte- 
J.C.R. Jones et al.

A

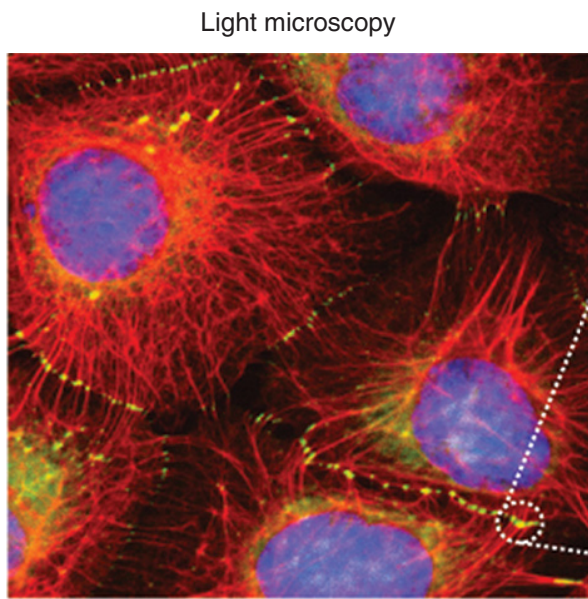

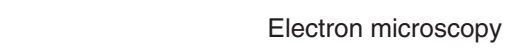

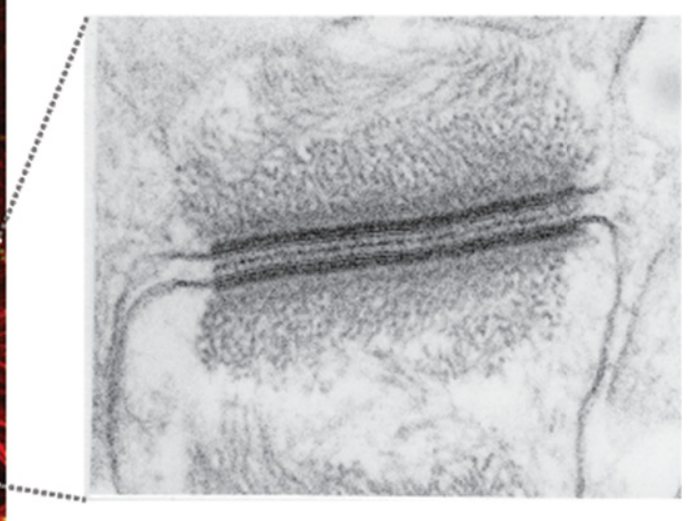

B

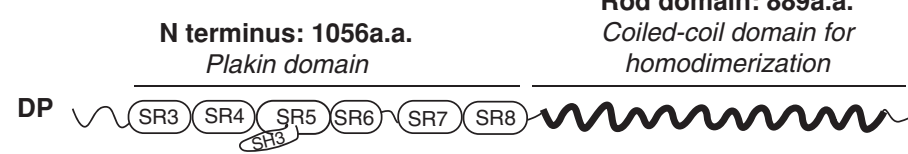

C terminus: 926a.a.

Plakin repeat domains and $C$ tail for IF binding
C

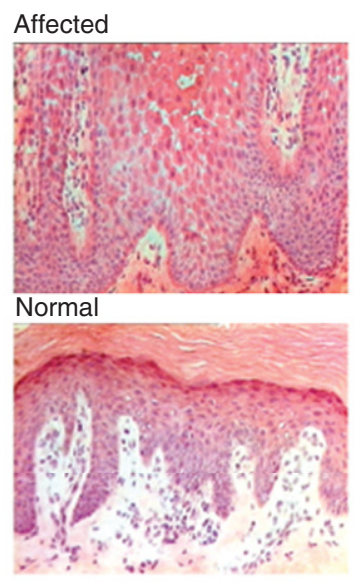

D

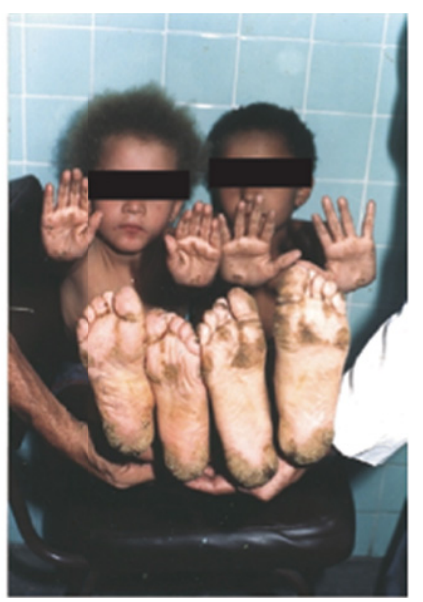

Figure 2. Desmoplakin (DP) and its role in tissue architecture. (A) (Left) Fluorescence microscopy image of human epidermoid carcinoma cells induced to express the truncated form of DP, DPNTP (green), and then immunostained for antibodies against endogenous keratin (red), revealing the localization of desmosomes (circled). (Right) An electron micrograph from bovine tongue epithelium illustrating the highly organized ultrastructure of the desmosome. (B) Schematic of the domains contained within full length wild-type DP. a.a., amino acids; PRD, plakin repeat domain; SH3, Src-homology 3 domain; SR, spectrin repeat; $\mathrm{N}$ terminus, amino terminus; C terminus, carboxyl terminus. (C) Histology of palmoplantar epidermis from (upper) an individual with Carvajal syndrome showing large intercellular spaces among suprabasal keratinocytes and (lower) a normal individual. (D) Clinical features showing the striate pattern of palmoplantar hyperkeratosis and woolly hair in two family members with Carvajal syndrome. ( $A$, Light microscopy image, adapted, with permission, from Green and Gaudry 2000; electron micrograph, adapted, with permission, from Kowalczyk et al. 1994; C,D, kindly provided by David Kelsell (Queen Mary, University of London, United Kingdom); D, adapted from Norgett et al. 2000, by permission of Oxford University Press.)

grate the cadherin, catenin, plakin, and IF components at cell junctions. A long-standing model postulates that, before desmosome assembly, two precursor compartments exist within the cell awaiting a signal to cluster at the plasma membrane (Pasdar et al. 1991). One compartment contains cadherins and Pg, whereas the second contains the
Pkp and plakin components (Jones and Goldman 1985). At low calcium concentrations, before integration at the membrane, the two compartments are visibly and biochemically distinguishable. Cadherins and Pg appear in vesicular, microtubule-associated structures. In contrast, Pkp and DP associate with cytoplasmic IFs (Godsel et al. 
2005). Dsg2 likely exploits this early association with the cytoskeleton as, upon cell-cell contact, Dsg2 traffics to the cell membrane along microtubules in a kinesin-driven manner (Nekrasova et al. 2011).

By definition, desmosomes anchor IFs at sites of desmosomal-cadherin-mediated adhesion. Although disrupting $\mathrm{Pg}-\mathrm{Dsg}$ or Pg-Dsc binding impairs IF anchorage, biochemical data suggest that Pkp and DP mediate the physical tethering of IFs to desmosomes (Bonne et al. 2003; Acehan et al. 2008). The integration of DP and Pkp at the nascent desmosome takes place in three phases: (1) de novo appearance of DP at sites of cell-cell contact following closely behind the appearance of Pkp-2; (2) formation of DP-enriched particles containing Pkp on cytoplasmic IFs; and (3) translocation of cytoplasmic DP-Pkp particles to the plasma membrane (Fig. 3) (Godsel et al. 2005).

The inclusion of Pkp in phase-2 DP particles represents a prerequisite for the third-translocation-phase. This is, at least in part, owing to its ability to recruit the calciumsensitive enzyme protein kinase $\mathrm{C} \alpha(\mathrm{PKC} \alpha)$ to IF-docked DP that, in turn, modulates the dynamics of DP-IF asso- ciation, likely through phosphorylation of DP and / or other components of the DP-IF complex (Bass-Zubek et al. 2008). Thus, failure to phosphorylate the complex essentially freezes the transition of DP from cytoplasmic IFs to the nascent cell junction. PKC-guided phosphorylation appears crucial to the reverse process as well. Kroger and colleagues have reported that the phosphorylation of DP destabilizes established desmosomes and promotes their endocytosis, a process that is repressed by a complex of keratin and Rack1, a Trp-Asp (WD) repeat protein, which binds and inactivates PKC $\alpha$ (Kroger et al. 2013).

More recent work has provided further insight into regulation of DP-IF assembly dynamics, showing that DP is modified by a GSK3 $\beta$-dependent processive phosphorylation cascade present in its extreme carboxy-terminal flexible region (Albrecht et al. 2015). Importantly, processive phosphorylation not only requires priming by phosphorylation of residue DP S2849, but also methylation of DP R2834 by PRMT-1 (protein arginine methyltransferase 1). A mutation in this latter methylation site has been reported in patients with arrhythmogenic cardiomyopathy,

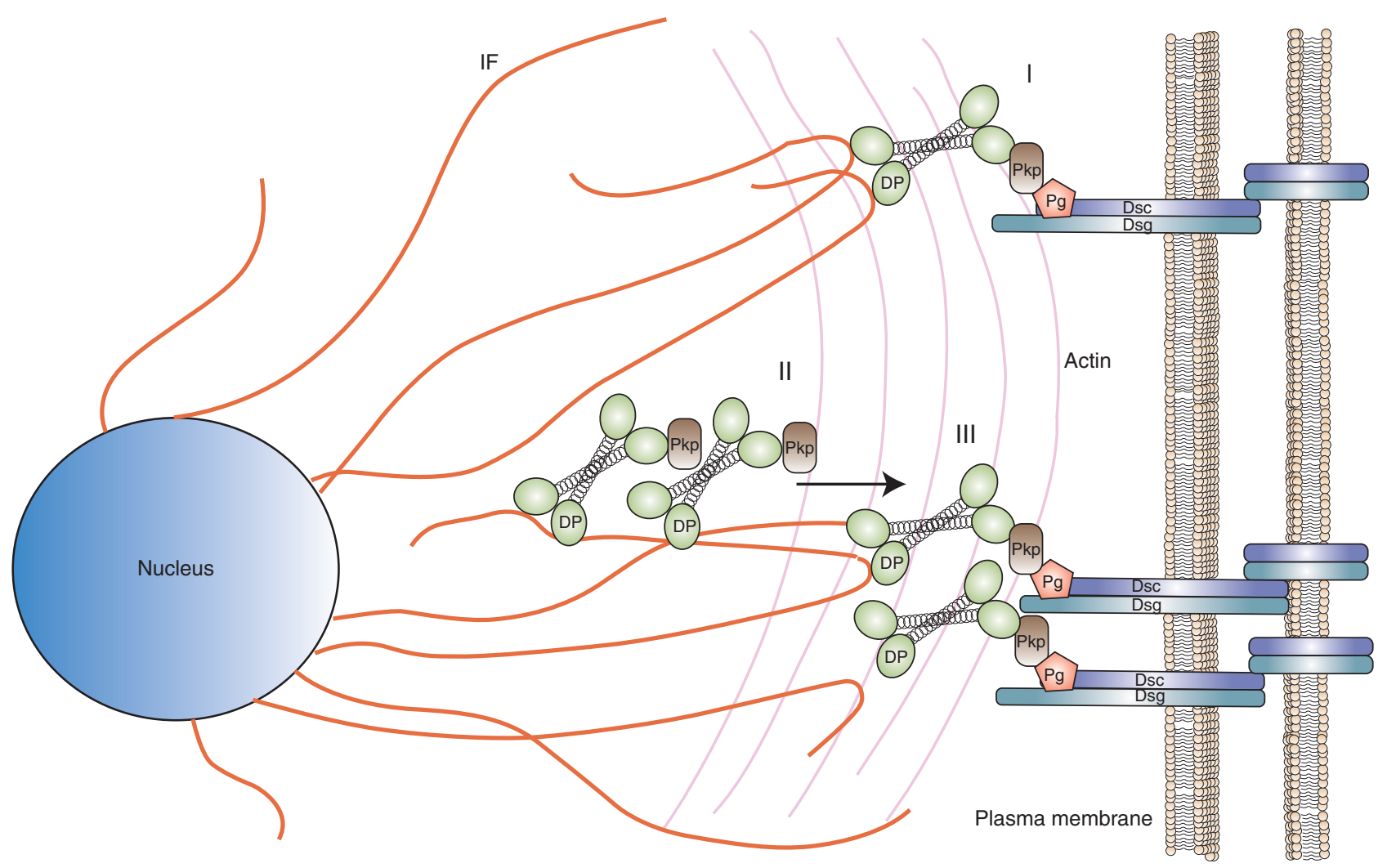

Figure 3. Model of desmoplakin (DP) assembly into desmosomes. The integration of DP and plakophilin (Pkp) occurs in three phases: (I) de novo appearance of DP at sites of cell-cell contact along with Pkp-2, (II) formation of DP-enriched particles containing Pkp on cytoplasmic intermediate filaments (orange strands), and (III) the translocation of cytoplasmic DP-Pkp particles to the plasma membrane. Dsc, desmocollin; Dsg, desmoglein; Pg, plakoglobin. 
leading to hypophosphorylation of DP and retention of DP on cytoplasmic desmin IFs. Whereas PKC was a logical candidate for the priming kinase in this cascade, inhibitor studies suggest that a kinase other than PKC is responsible for initiating the cascade, leaving open the question of what PKC substrates contribute to DP-IF dynamics.

In contrast to the trafficking of Dsg and Dsc along microtubules, however, the association of Pkp and DP with IFs offers no obvious access to motor-driven, directional transport. Studies suggest that phase-3 of desmosomal plaque assembly depends on the actin cytoskeleton (Godsel et al. 2005). More specifically, pharmacological blockade of actin remodeling disrupts the transfer of DP and Pkp to nascent desmosomes. In addition to recruiting PKC to DP, Pkp can also localize RhoA activity to sites of cell-cell adhesion and, in so doing, provides a means for modulating actin contractility so as to promote the delivery of DP/Pkp particles and, possibly, associated IFs to the plasma membrane (Godsel et al. 2010). Temporal studies using live-cell imaging indicate that the transfer of DP/Pkp particles begins $\sim 30 \mathrm{~min}$ after cells establish cell contacts. This suggests that cadherin engagement and organization at the cell surface precede phase 3 and, thus, provide a "target" for plaque assembly (Watt et al. 1984).

This assumption, however, highlights a gap in our understanding of desmosome assembly. To date, techniques required to track multiple components in real time have limited in-depth analysis of desmosomal assembly to a small number of cultured cell lines. As Dsg/Dsc trafficking analysis relies heavily on Dsg2 and Dsc2, specifically, the tracking of plaque components has focused on Pkp-2 (Godsel et al. 2005). Whether similar or altogether different mechanisms are used to assemble desmosomes in cultured primary cells or in vivo, where multiple Dsc, Dsg, and Pkp isoforms coexist, awaits investigation. Nor are the circumstances under which the two precursor compartments unite well understood. Moreover, at homeostasis, even stable desmosomes continually integrate newly synthesized components and jettison existing components (Windoffer et al. 2002). These phenomena, in the context of organismal biology, remain understudied, as do the particular dynamics of IF cables at sites of desmosomal adhesion.

In vivo, epidermal desmosomes become calcium-independent, a state known as hyperadhesive, after their initial establishment (Garrod and Kimura 2008). In addition to its role in desmosome assembly discussed above, PKC $\alpha$ plays a particularly important role in this process. After wounding, desmosomes revert to calcium dependence, a transition marked by the activation and translocation of PKC $\alpha$ to desmosomal plaques (Wallis et al. 2000). PKC inhibitors restore hyperadhesiveness to the wound edge, suggesting that PKC activity is crucial for mainte- nance of a calcium-dependent state. Importantly, mutation of the priming site that initiates DP processive phosphorylation (S2849G) enhances DP-IF association and strengthens intercellular adhesion. The resulting epithelial sheets show reduced calcium depletion and PKC activation (Hobbs et al. 2011). These data support the idea that adhesion strengthening depends on IF association with DP and raise the possibility that modulation of DP-IF dynamics play a role in wound healing and other processes involving epithelial remodeling.

PKC manipulations do alter the intercellular morphology of desmosomes visible by EM (Garrod et al. 2005). Presumably, this mechanism exists to facilitate transitions between states requiring impermanent junctions, such as migration, versus those requiring stable cellular cohesion, such as the maintenance of epithelial barriers.

\subsection{Scaffolding and Signaling at Desmosomes}

Recent literature provides evidence that desmosomal proteins regulate processes that do not directly contribute to desmosomal adhesion per se. Cardiac tissue provides a useful example. In cardiac myocytes, the site adjoining neighboring cells is referred to as the ID. The ID was originally described as a specialized structure that contains three junctional complexes-AJs, desmosomes, and gap junctions (Kowalczyk and Green 2013). However, within the ID, specialized hybrid junctions form whereby both AJs and desmosomes intermingle while being closely associated with gap junctions (Fig. 4A) (Borrmann et al. 2006). The existence of these hybrid cardiac junctions, termed area composita, has been substantiated with the discovery that $\alpha \mathrm{T}$-catenin interacts specifically with the desmosomal plakophilin Pkp-2 (Fig. 4B) (Goossens et al. 2007).

Arrhythmogenic cardiomyopathy (AC) has been dubbed a disease of the desmosome as $>50 \%$ of the mutations associated with this disease encode desmosomal components (Rizzo et al. 2012). This disease is characterized by loss of integrity of IDs, loss of cardiomyocytes, and replacement of fibro-fatty tissue (Fig. 4C). These defects eventually result in electrical instability, ventricular arrhythmias, and ultimately reduced contractility and heart failure (Rizzo et al. 2012). One of the hallmarks of AC is recurrent ventricular arrhythmias, consistent with the finding that many patients display decreased membrane localization of the gap junction molecule connexin 43 (Cx43). This phenomenon is highlighted by the aforementioned studies utilizing in vivo mouse models of cardiac-restricted homozygous or heterozygous deletion of the gene encoding DP (GarciaGras et al. 2006; Lyon et al. 2014). These models show the importance of DP to cardiac conduction and repolarization as loss of DP is sufficient to cause significant $\mathrm{Cx} 43$ misre- 
A

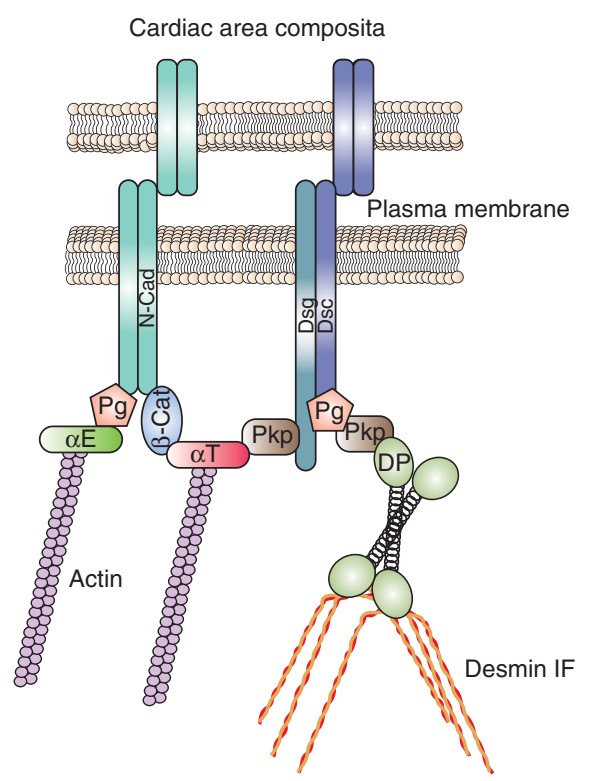

B

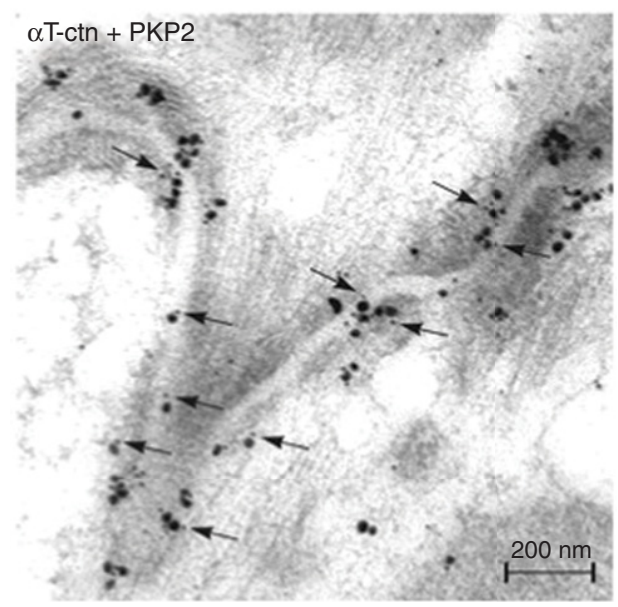

C
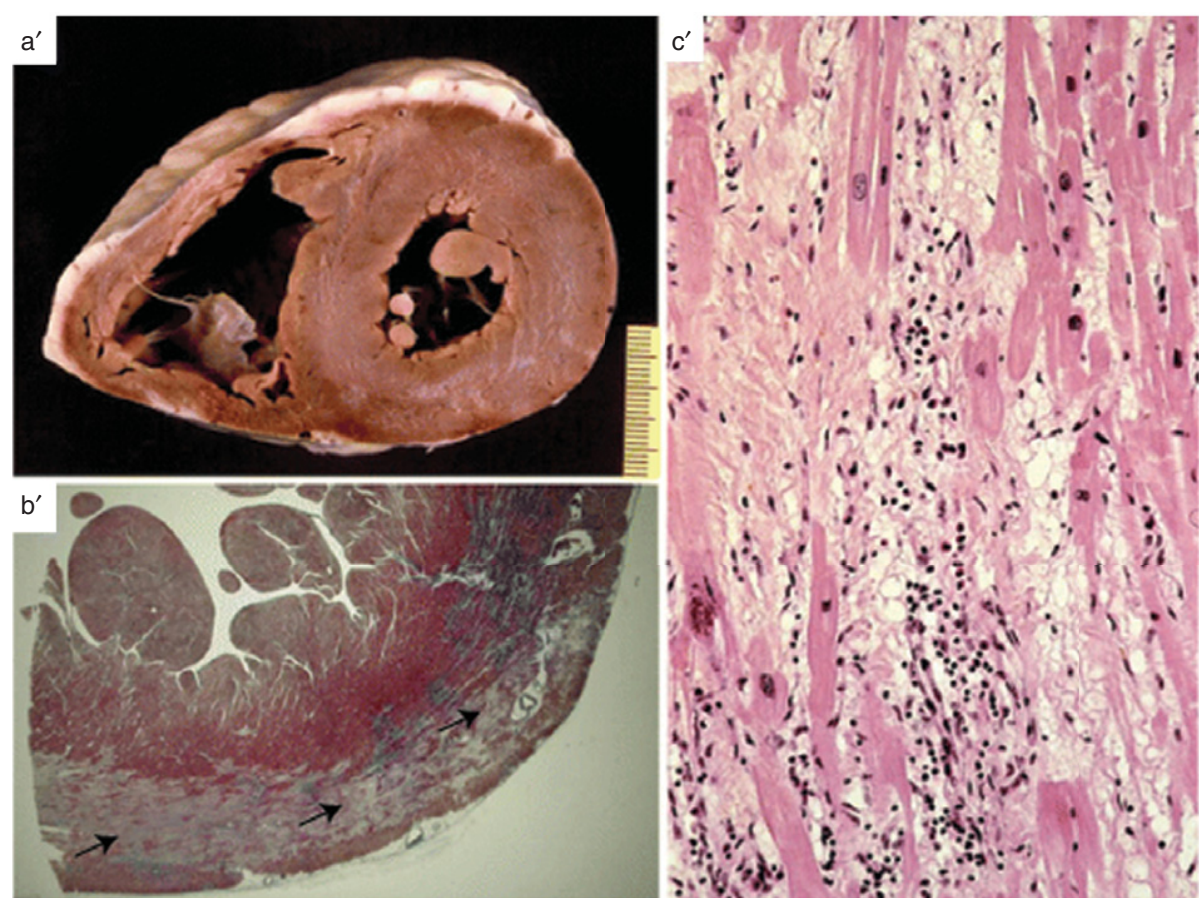

Figure 4. Role of desmosomes in specialized cardiac structures in health and disease. (A) Schematic of the cardiac area composita. $\alpha \mathrm{T}$, $\alpha \mathrm{T}$-catenin; $\alpha \mathrm{E}, \alpha \mathrm{E}$-catenin; DP, desmoplakin; Dsc, desmocollin (a cadherin); Dsg, desmoglein (a cadherin); IF, intermediate filament; N-cad, N-cadherin; Pg, plakoglobin; Pkp, plakophilin. (B) Immuno-electron micrograph showing colocalization of $\alpha \mathrm{T}$-catenin and Pkp-2 at adhering junctions of the intercalated discs of cardiomyocytes. Consecutive double labeling at the area composita shows $\alpha \mathrm{T}$-catenin by silver amplification (large dots) and Pkp-2 labeling (10-nm gold particles [small dots, arrows]). (C) Early-stage arrhythmogenic cardiomyopathy (AC) in a patient carrying a desmoplakin mutation. $\left(a^{\prime}\right)$ Cross section of the patient's heart (scale bar in centimeters). ( $b^{\prime}$ ) Panoramic histologic view of the posterolateral left ventricular wall showing a subepicardial band (black arrows) of acute-subacute myocyte necrosis. $\left(c^{\prime}\right)$ Histology showing myocyte necrosis and myocytolysis associated with polymorphous inflammatory infiltrates, together with early fibrous and fatty tissue repair. ( $B$, Image kindly provided by Frans van Roy, Ghent University, Ghent; reprinted from Goosens et al. 2007, with permission from Company of Biologists; $C$, images kindly provided by Cristina Basso, University of Padua Medical School, Padua, Italy.) (Reprinted from Rizzo et al. 2012, with kind permission from Springer Science \& Business Media.) 
gulation in terms of both its expression and localization (Lyon et al. 2014). Although it is clear that DP is playing an important role in regulating Cx43 gap junction stability/ formation, the mechanism(s) by which it is able to do so are still poorly understood. It is possible that DP supports cardiac gap junctions, at least in part, by providing a stable mechanical environment. However, DP might also regulate connexin recruitment to the ID through a recently described cortical-microtubule-capture mechanism mediated by the leucine-zipper end-binding protein EB1 binding to the DP amino terminus (Patel et al. 2014).

Furthermore, cardiac-restricted depletion of DP was also shown to lead to nuclear localization of Pg and reduction in canonical Wnt/ $\beta$-catenin signaling through TCF/ Lef1 transcription factors, resulting in increased expression of adipogenic and fibrotic genes, thus elucidating one of the possible mechanisms of AC pathogenesis (Garcia-Gras et al. 2006). This highlights the multifunctional properties of armadillo proteins - in this instance Pg-outside their traditional adhesion functions (Hatzfeld et al. 2014).

In addition to DP and the armadillo proteins, desmosomal cadherins have also been found to perform signaling roles. Of note, Dsg1 has been shown to be an important regulator of keratinocyte differentiation as loss of Dsg1 results in disrupted epidermal differentiation and suprabasal morphogenesis (Getsios et al. 2009). Dsg1 was found to regulate the signaling pathways that govern differentiation via a novel binding partner, Erbin ("ErbB2 interacting protein"). The Dsg1-Erbin interaction is required to suppress ERK signaling for keratinocyte differentiation to proceed (Harmon et al. 2013).

\subsection{Desmosome-IF Functions}

What specific contributions are made by the IFs to desmosomal function? What consequences would have arisen had desmosomes been programmed to recruit only actin? In this regard, DP knockout mice form desmosomes, but the structures fail to anchor keratin, resulting in a physical weakening of cell-cell adhesions (Vasioukhin et al. 2001). Thus, desmosomal adhesion requires IF attachment. Likewise, the cells of certain tissues depend on desmosomes to maintain cellular cohesion, implying that desmosome-IF complexes evolved to provide a brand of adhesion not supported by the more ancient, actin-based AJ (Jefferson et al. 2004; see Bachir et al. 2016). A reasonable hypothesis would suggest that desmosomes emerged to exploit the strength of IFs for the purposes of preserving tissue under mechanical strain (Kreplak et al. 2008; Leitner et al. 2012).

There is now considerable evidence that, in addition to mediating adhesion, cell-junctional complexes, such as AJs and FAs, are capable of acting as mechanosensors by responding to mechanical cues (Barry et al. 2014). The ability of these junctional complexes to regulate mechanotransduction is directly tied to the fact that they are coupled to the actin cytoskeleton and are able to sense changes in external force via actomyosin contractility. Given the elasticity of IFs and their important role in providing mechanical stability to cells under tension, it is plausible that proteins tethered to IFs have the potential to act as mechanosensors. In this context, the possibility that desmosomal components might act as mechanosensors has received little attention. However, the discovery that cadherins transmit mechanical information through IFs provides support for this possibility (Weber et al. 2012).

With the exception of data indicating Pkp modulation of in vitro IF network assembly, few studies have attempted to assess whether desmosomes alter, guide, or otherwise exploit the self-assembling capacity of IF networks (Hofmann et al. 2000). DP, the desmosomal IF cytolinker, would appear to be a logical candidate for this role. Indeed, evidence exists in the literature that implicates a function for DP in regulating the oligomeric state of IFs. In cultured cells, expression of DP constructs containing the IF-binding carboxy-terminal domain results in the reorganization of their IF networks and the accumulation of the mutant protein in fine filamentous arrays (Stappenbeck and Green 1992). These arrays resemble the desmosomal plaque, suggesting that cooligomerization of DP and IFs into smallcaliber filaments drives formation of the junctional plaque structure. Additionally, DP is translocated to the cell surface in association with IFs during the formation of desmosomes, again suggestive of a role for DP in the modulation of IF dynamics (Jones and Goldman 1985). Like desmosomal cadherins and Pkp, keratins display tissue- and differentiation-specific expression patterns. However, it remains unclear whether different keratins uniquely modulate or support, for example, the differential signaling attributed to individual desmoglein isoforms.

\section{NONDESMOSOMAL IF MEMBRANE COMPLEXES}

Desmosomes represent the best-studied IF-cadherin structure but appeared relatively late in evolutionary terms. The architectural anchorage of IFs at cadherins, however, might have more primal roots. Mesendodermal cells of the amphibian Xenopus establish C-cadherin junctions linked intracellularly to IFs through $\mathrm{Pg}$ (Weber et al. 2012). Xenopus lack a full DP counterpart despite expressing proteins that contain sections of DP-like domains. It remains unclear, then, whether Pg binds to IFs directly in this case. Regardless, the importance of this unusual junction lies in an ability to transmit extracellular mechanical information to cells along the leading edge of a wound or 
migrating tissue. After allowing C-cadherin-coated beads to adhere to cultured Xenopus cells, application of a force directed so as to remove the bead from the cell elicits recruitment of Pg and keratin to the site of C-cadherinmediated adhesion. The cell responds, in turn, by engaging machinery required to promote migration in the opposite direction. Thus, in vivo, it appears likely that migration of cell sheets en masse into an open space is directed by $\mathrm{C}$-cadherin-Pg-IF junctions formed on the posterior end of cells at the leading edge.

In mammalian cells that lack desmosomal components, IF-cadherin complexes are also important in cell and tissue organization. For example, lens cells undergo a process of differentiation during which a basal layer of epithelial cells gives rise to superficial, highly organized, hexagonal fiber cells (Song et al. 2009). The geometry of these cells and their optical properties depend heavily on the integrity of the IF components phakinin (CP49) and filensin (CP115), which, together with $\alpha$-crystallin, combine to form supramolecular structures termed beaded filaments (Song et al. 2009). The expression of mutant forms of both proteins is correlated with the development of cataracts, implicating a role for these proteins in lens cell and tissue organization. In support of this, in fiber cells, both vimentin and beaded filaments terminate at junctional complexes established by $\mathrm{N}$-cadherin, cadherin-11, Pg, periplakin, and plectin (Leonard et al. 2008; Yoon and FitzGerald 2009). Intriguingly, these cadherin-IF complexes congregate along the short edge of the hexagonal cells, whereas, along the long edge, beaded filaments feed into desmoyokin (AHNAK)/ periplakin-based adhesions (Straub et al. 2003).

\section{THE HEMIDESMOSOME}

In addition to their interactions with cell-cell contact sites, IFs also show connections with regions of cell-matrix adhesion, both in cultured cells and tissues. The most impressive of the entities that mediate interaction between IFs and the cell surface, at least in EM images, is the HD (Figs. 1 and 5). For details of HD structure and function, readers are referred to reviews published elsewhere (Jones et al. 1998; Borradori and Sonnenberg 1999; de Pereda et al. 2009).

HDs are found in epithelial cells of tissues subject to mechanical stress, including the skin and bladder. At the ultrastructural level, HDs appear as "spot welds" comprising tripartite plaques (two regions of electron density, separated by a clear zone) at areas where epithelial cells abut the basement membrane zone (BMZ), which comprises extracellular matrix (ECM) (Figs. 1 and 5). Their role in stabilizing cell-ECM interaction is well established as HD loss is accompanied by blistering as a result of dys-adhesion of the epithelial layers and ECM (Fine 2007).
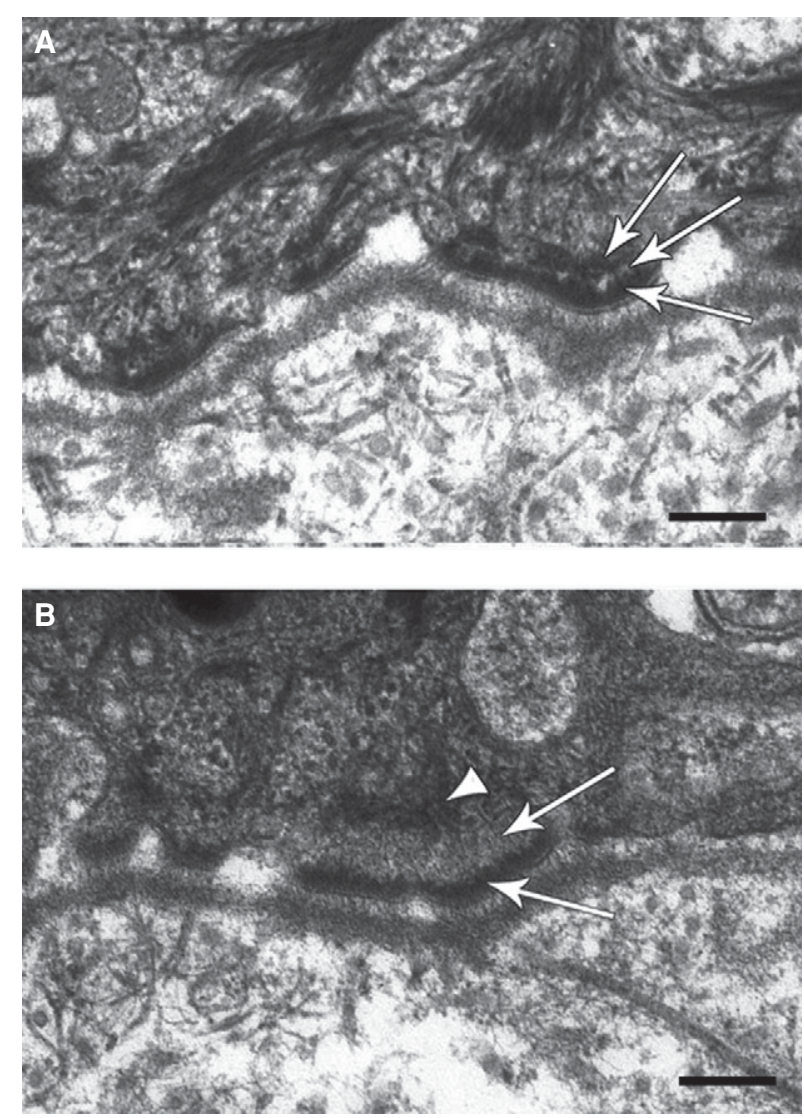

Figure 5. A role for BPAG1 in mediating anchorage of intermediate filaments (IFs) at hemidesmosomes (HDs). (A) Electron micrograph of a section of typical human skin at the region of interaction between keratinocytes and the basement membrane zone (BMZ). Three HDs are shown, each possessing a tripartite plaque (arrows). Note that IFs show extensive interaction with the inner HD plaque. (B) Electron micrograph of a comparable region of the skin of a patient showing loss of expression of bullous pemphigoid antigen 1 (BPAG1). The arrowhead indicates that the HD plaque lacks an obvious inner layer, and the arrows mark the keratin IF interaction with the HD that is also abnormal. Scale bar, $100 \mathrm{~nm}$. (Images kindly provided by John McGrath, King's College, London, and James McMillan, St Thomas' Hospital, London). ( $A, B$ Adapted from Groves et al. 2010, with permission from Macmillan Publishers Ltd.)

IFs bind to the inner cytoplasmic, electron-dense zone of each HD plaque in a manner similar to IF-desmosome plaque interaction. Indeed, the term "hemidesmosome" was coined because of the similarity in appearance of the $\mathrm{HD}$ and desmosomal plaques and their association with the IF cytoskeleton. However, despite their resemblance, the HD and desmosome are distinct in their protein composition (Green and Jones 1996).

\subsection{IF-Associated Proteins in the HD}

The matrix receptor $\alpha 6 \beta 4$ integrin is the core element of the HD (Fig. 1). It tethers, albeit indirectly, IFs to the cell 
surface in the cytoplasm and binds extracellularly to laminin-332, its ligand within the BMZ. In addition, $\alpha 6 \beta 4$ integrin mediates signal transmission from the ECM to the cytoskeleton (Mainiero et al. 1997; Mercurio et al. 2001; Tsuruta et al. 2003). The $\beta 4$ integrin is unique among the $\beta$ integrins because it has a cytoplasmic tail of 1000 amino acids that allows it to interact directly with a number of molecules involved in its interaction with the IF cytoskeleton, as will be detailed below (Borradori and Sonnenberg 1996).

In the cytoplasm of certain epithelial cells, the tail of the $\beta 4$ subunit of $\alpha 6 \beta 4$ integrin interacts directly with three proteins, the two bullous pemphigoid (BP) antigens (BPAG1 and BPAG2), first characterized using autoantibodies in the sera of patients with BP, and plectin, all of which play a role in tethering IFs to the cell surface (Hopkinson and Jones 2000; Koster et al. 2003). BPAG1 (also known as BP230) is a $230-\mathrm{kDa}$ protein that belongs to the plakin family and, hence, is a relative of the DP protein described above (Jefferson et al. 2007). There are two isoforms of the BPAG1 protein: one found in HDs, and one expressed in neurons, termed BPAG1e and BPAG1n, respectively (Guo et al. 1995). These isoforms possess distinct amino-terminal domains and show different cytoskeleton interactions. Specifically, BPAG1n cross-links neurofilaments with the actin cytoskeleton, whereas BPAGle mediates interaction of keratin IFs with the cell surface at the site of HDs (Yang et al. 1996).

Isolated BPAGle molecules appear dumbbell-shaped, with globular ends and a central $\alpha$-helical rod, and likely form dimers (Klatte and Jones 1994). The carboxy-terminal globular domain binds directly to keratin Ifs, as well as the cytoplasmic tail of $\beta 4$ integrin (Fontao et al. 2003; Koster et al. 2003). The amino-terminal domain of BPAGle also interacts with the amino terminus of the second BP antigen BPAG2 (also known as BP180 or collagen type XVII), a type II transmembrane protein with a collagen-like extracellular domain that binds laminin-332 in the BMZ (Hopkinson and Jones 2000; Koster et al. 2003; Van den Bergh et al. 2011). In addition, BPAG2 also interacts with $\beta 4$ integrin in the cytoplasm and with $\alpha 6$ integrin extracellularly (Hopkinson et al. 1995; Hopkinson and Jones 2000). Yeast two-hybrid assays also identify an interaction between BPAG1 and $\beta 4$ integrin, although this association appears relatively weak (Hopkinson and Jones 2000).

Functionally, BPAG1 is an essential IF linker at the cell surface as the HDs in the skin of BPAG1 knockout mice lack keratin association (Guo et al. 1995). However, the HDs in such mice still maintain reasonably strong cell-matrix associations as disruption of the epidermal-dermal interaction only occurs following mechanical trauma. Recently, homozygous mutations in the gene encoding BPAG1 have been identified in a patient with skin fragility. The HDs in these individuals lack an inner plaque, and keratin IFs fail to be properly secured to the cell surface-this is consistent with the importance of BPAG1 in mediating IF-HD anchorage (Fig. 5) (Groves et al. 2010).

Intriguingly, wound healing is inhibited in BPAG1 knockout mice (Guo et al. 1995). Moreover, epidermal cells with reduced expression of BPAG1 show migration defects, indicating that BPAG1 plays a role in regulating keratinocyte motility during wound healing. It appears to function as a scaffold for the small GTPase Rac that, in turn, regulates the activation state of cofilin, an actin-severing protein involved in establishment of cell polarity and extension of the moving front of migrating skin cells (Hamill et al. 2009).

In addition to BPAGle, isoform 1a of its plakin relative plectin is a component of the HD plaque. Like BPAG1, plectin exists as a dimer, is dumbbell shaped, comprises a rod flanked by globular ends, and mediates the association of IFs with $\alpha 6 \beta 4$ integrin (reviewed in Castañón et al. 2013; see also Liem 2016). Plectin possesses binding sites for $\beta 4$ integrin at both its amino and carboxyl termini (Rezniczek et al. 1998). It interacts with IFs through sites within its globular carboxyl terminus. Although plectin contains an actin-binding site toward its amino terminus, this overlaps with the $\beta 4$-integrin-binding domain such that the plectin interaction with $\beta 4$ integrin inhibits its association with actin (Koster et al. 2003). Loss of plectin in human patients with a variant of the blistering skin disease epidermolysis bullosa associated with muscular dystrophy (EB-MD) results in dys-adhesion of epidermal cells from the BMZ, predicted to be the result of poorly formed HDs that lack connections with the IF cytoskeleton (Uitto et al. 1996).

Interestingly, in the BPAG1-null mouse, the presence of plectin in the HD plaque of the skin is unable to compensate for the absence of BPAG1e, at least with respect to IF interaction (Guo et al. 1995). This implies that there is some cross talk or cooperativity of these two plakin family members in mediating the anchorage of IFs to the HD plaque. In this regard, plectin is also associated with $\alpha 6 \beta 4$ integrin in epithelial cells, such as those lining the gut, which lack expression of the BP antigens. Under such circumstances, the plectin $-\alpha 6 \beta 4$ integrin protein complexes have been termed type II HDs (Fontao et al. 1999). These possess indistinct cytoplasmic plaques, and whether they interact with IFs is unclear.

Plectin directly binds keratin through a linker region between the fifth and sixth plakin modules within its carboxyl terminus, and this interaction is regulated by phosphorylation at serine 4642 (Bouameur et al. 2013; Winter and Wiche 2013). Plectin isoform 1a then mediates IF interaction with the cell surface by binding to the connecting 
segment and actin-binding domain of the $\beta 4$ integrin subunit (Rezniczek et al. 1998). The latter interactions are modulated by $\mathrm{Ca}^{2+}$, which appears to be a key regulator of the integrity of HD protein complexes. Specifically, on an increase in cytoplasmic levels of $\mathrm{Ca}^{2+}$, protein kinase $\mathrm{C} \alpha$ phosphorylates serine residues within the connecting segment of the $\beta 4$ integrin subunit (Rabinovitz et al. 2004). In addition, calmodulin binds the actin-binding domain of plectin (Kostan et al. 2009). These two events appear essential for the dissociation of plectin from the $\alpha 6 \beta 4$ integrin heterodimer and a loss of interaction between the IFs and the cell surface. Such disassembly is necessary during wound healing to allow a cell to release itself from the constraints of the BMZ and move over the wound bed.

\subsection{IF Functions at the Site of the HD}

The HDs of mouse and human epidermal cells that lack or have abnormal keratin IF connections show defects in adhesion to the dermis. Although there is no direct evidence that IFs are required for stabilizing matrix attachment mediated by HDs, keratin knockout keratinocytes are slower to attach than their keratin-expressing counterparts, supporting a likely role for IFs in regulating HD adhesion functions (Seltmann et al. 2013). Moreover, there is evidence that one function for IFs is to regulate the distribution of HD components along sites of cell-ECM interaction (Seltmann et al. 2013). Specifically, in keratin knockout keratinocytes, unlike their wild-type counterparts, plectin fails to codistribute with $\alpha 6 \beta 4$ integrin (Seltmann et al. 2013). Indeed, keratins appear to stabilize a plectin- $\beta 4$ integrin association by regulating $\beta 4$ integrin posttranslational modification. By doing so, keratins inhibit $\beta 4$ integrin turnover and promote HD stabilization (Seltmann et al. 2015).

There are numerous studies indicating that $\alpha 6 \beta 4$ integrin and its associated proteins, including the BP antigens, are involved in mediating signaling that regulates migration and proliferation (Mainiero et al. 1997; Mercurio et al. 2001; Tsuruta et al. 2003; Hamill et al. 2009). This evidence has been generated primarily from cells in culture that, in most instances, do not assemble bona fide HDs. Rather, such cells possess $\alpha 6 \beta 4$-integrin-rich HD protein complexes that have been demonstrated to exhibit interactions with various signaling intermediates, including Racl. Whether such complexes interact with IFs remains unclear, leaving open the possibility that IF association is a requirement for assembly of a bona fide association. Thus, IF interaction with HD protein complexes might actually inhibit, rather than promote, integrin-mediated signaling. This is in contrast to the case for FAs, whose association with IFs appears to facilitate FA signaling, as we discuss in Section 6.

\section{$6 \quad$ IFs AND FAs}

\subsection{Interactions between Vimentin and FAs}

FAs, also termed focal contacts, were first identified in chick heart fibroblasts by EM as electron-dense plaques with longitudinal filaments (Abercrombie et al. 1971). At its core, each FA, like the HD, contains an integrin heterodimer that mediates interaction of the cell with its ECM and tethers the cytoskeleton to the cell surface in the cytoplasm. However, unlike the HDs, numerous integrin heterodimers have been identified in FAs. Indeed, at the molecular level, the FA is a far more complex structure than the HD as more than 150 proteins have been characterized as being FA components (Geiger et al. 2001; Zamir and Geiger 2001). Consistent with this complexity, FAs are involved in a variety of cellular functions, including adhesion, signaling, scaffolding, mechanosensing, and generating the traction forces necessary for cell motility. There are numerous excellent reviews detailing the structure and functions of FAs in cultured cells in two- and three-dimensional culture (Cukierman et al. 2002; Wozniak et al. 2004; Ziaidel-Bar et al. 2004; Lo 2006). Here, we focus on reviewing data indicating a role for FAs as cell-surface anchorage sites for IFs, in particular the vimentin and keratin cytoskeletons. This is a less wellstudied and understood aspect of FA biology (see Bachir et al. 2016).

FAs are dynamic structures that can alter their morphology and change their constituents, depending on various environmental cues and whether a cell is motile or stationary (Zamir et al. 1999; Katz et al. 2000; Galbraith et al. 2002; Ziaidel-Bar et al. 2004). Nascent FAs (focal complexes) assemble at the cell periphery when an integrin heterodimer interacts with its ligand in the ECM, resulting in integrin clustering and activation. The latter involves binding of a talin and/or a kindlin family member to the integrin cytoplasmic tails, resulting in precise conformational changes that facilitate additional protein recruitment, as well as association of a variety of signaling intermediates. As the complex matures, increased forces generated by actomyosin drive growth of the nascent FA, leading to an elongation of its structure (Zamir et al. 1999; Galbraith et al. 2002; Geiger et al. 2009). Interaction with actomyosin creates traction forces that also influence bidirectional signaling (Zamir and Geiger 2001). In certain cells, under continued tension, integrins and their associated matrix receptors, including the syndecans, modulate matrix formation and structure. For example, these receptors induce fibronectin formation into fibrils, which trigger FA "maturation" into a fibrillar adhesion matrix attachment device containing tensin (Katz et al. 2000; Galbraith et al. 2002).

More than 25 years ago, Bershadsky and colleagues observed a colocalization of vimentin- and vinculin-contain- 
ing adhesion plaques in quail embryo fibroblasts (Bershadsky et al. 1987). Indeed, these same investigators also presented data indicating that microtubules are involved in routing IFs to FAs. That IFs might be involved in FA structure/function is supported by analyses of fibroblasts isolated from vimentin knockout embryos. The cells show aberrantly bundled microfilaments, changes in FA protein organization, abnormal matrix adhesion, and a dramatic reduction in ability to generate traction forces, leading to impaired migration (Eckes et al. 1998; Eckes et al. 2000). Moreover, vimentin IF-FA interaction has also been described in cultured primary and transformed microvascular endothelial cells. In such cells, vimentin IFs appear to terminate or wrap around vinculin- and $\alpha \mathrm{v} \beta 3$-integrinpositive substrate attachment sites, leading to the latter being termed "vimentin-associated matrix adhesions" (VMAs) (Gonzales et al. 2001). In addition, in live endothelial cells, vimentin has been observed targeting to FAs, and FAs might act to nucleate vimentin filament elongation (Tsuruta and Jones 2003).

There are a number of potential mechanisms by which IFs are recruited to FAs. Vimentin might simply "tag along" with actin as actin has numerous binding partners within the FA. Purified vimentin and actin filaments are capable of directly interacting, possibly through the tail domain of vimentin (Esue et al. 2006). Another possibility is that vimentin interacts, most likely indirectly, with integrins in the FA, in a manner similar to the IF-HD association discussed above. Indeed, in endothelial cells grown on collagen, Kreis and colleagues identified vimentin in a complex with the tails of $\alpha 2 \beta 1$ integrin (Kreis et al. 2005). Furthermore, immunofluorescence localization supported the existence of a vimentin-integrin interaction as almost $20 \%$ of the FAs in the cells assessed showed colocalization of vimentin and the $\alpha 2$ integrin subunit (Kreis et al. 2005). In a more recent study, Bhattacharya and colleagues also used endothelial cells and showed that vimentin associates with FAs enriched in $\beta 3$ integrin subunits. When $\beta 3$ integrin was knocked down using short interfering RNA (siRNA), vimentin failed to associate with FAs when compared with its localization in untreated cells (Bhattacharya et al. 2009).

The most obvious candidate linker that could tether IFs to the FA is plectin. Indeed, there is support for this possibility. First, plectin is found associated with FAs in a variety of cells (Wiche and Baker 1982; Foisner et al. 1988; Gonzales et al. 2001). Second, knockdown of plectin expression in endothelial cells results in decreased recruitment of vimentin to FAs, a process that requires microtubules and the molecular motor kinesin (Bhattacharya et al. 2009). Interestingly, however, data from one set of investigators suggest that loss of plectin has no effect on the association of vimentin IF with FAs once such an interaction has been established (Bhattacharya et al. 2009). The latter might be an endothelial-cell-specific phenomenon as other investigators have reported, in fibroblasts, that plectin is necessary for both mediating and maintaining vimentin-FA interactions (Burgstaller et al. 2010). Indeed, Burgstaller and colleagues have identified the plectin isoform If as a crucial linker of vimentin IFs to FAs in fibroblasts. Moreover, these same investigators have presented evidence that plectin serves as a so-called "docking site and assembly center" for the vimentin IF cytoskeleton (Spurny et al. 2008; Burgstaller et al. 2010). In the absence of plectin If in fibroblasts, vimentin filaments show no interaction with FAs and extend beyond FAs to the cell edge (Burgstaller et al. 2010). In addition, plectin-1f-mediated targeting of vimentin to FAs requires some sort of cooperation of the plectin actin-binding domain and its $1 \mathrm{f}$-specific sequence. Interestingly, FAs in fibroblasts appear to nucleate the assembly of vimentin filaments from their intermediates, through plectin. A similar phenomenon is also seen in MCF7 cells. These cells normally express keratin, however, when induced to express vimentin, filament assembly appears to initiate at FAs in the periphery of the cells (Fig. 6A).

\subsection{Interactions between Keratin and FAs}

Keratin-FA interactions were first documented by Windoffer and colleagues, who showed that, in certain epithelial cells, FAs toward the cell periphery act as sites of nucleation of the keratin cytoskeleton (Windoffer et al. 2006). Indeed, these same investigators speculated that FAs are the IF equivalent of the microtubule-organizing center (MTOC), a suggestion supported by other studies mentioned above that reveal that newly synthesized vimentin IFs appear to assemble from FAs. Moreover, more recently, keratin IF interaction with an unusually arranged set of FAs has been observed in primary epithelial cells isolated from the alveolar compartment of the lung (Eisenberg et al. 2013). In these cells, keratin IFs wrap around a group of FAs located toward the center of the cells (Fig. 6B; see below for a more detailed description of these FAs).

\subsection{IF Functions at the Site of the FA}

A number of studies indicate that vimentin regulates FA structure and/or function. For example, loss of vimentin expression in endothelial cells following siRNA-mediated knockdown results in a reduction in both the size and stability of FAs. Moreover, the knockdown cells are also less adhesive than their normal counterparts under conditions of mechanostimulation induced by flow (Tsuruta and Jones 2003). Additionally, epithelial cells forced to express vimen- 

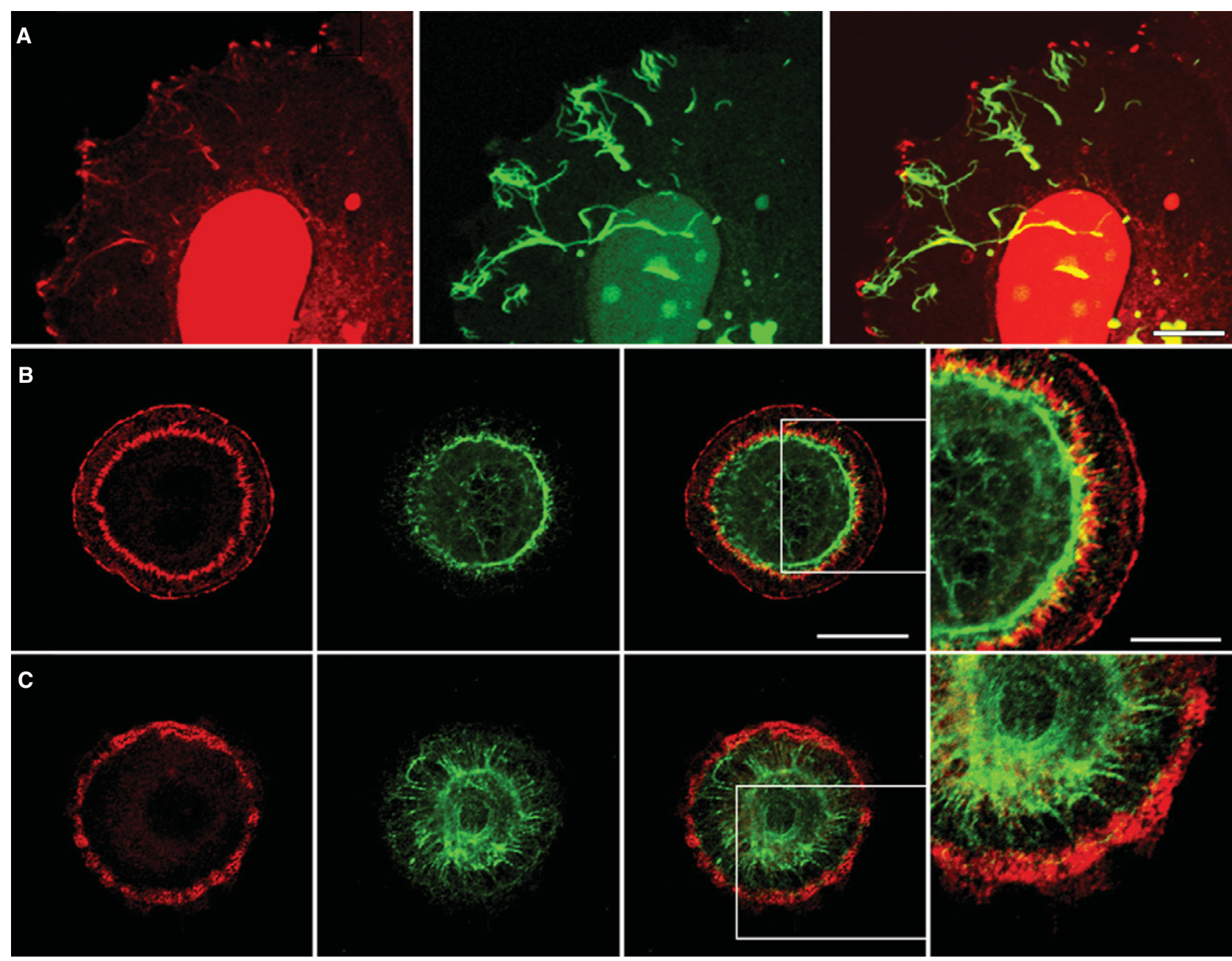

Figure 6. Interactions between focal adhesions (FAs) and the cytoskeleton. ( $A$ ) Human breast adenocarcinoma MCF7 cells induced to express vimentin tagged with green fluorescent protein and then fixed and stained with antibodies against $\beta 3$ integrin (red). The cells, when made to express vimentin, initiate filament assembly at FAs in the periphery of the cells. The prominent nuclear stain is an artifact. Scale bar, $10 \mu \mathrm{m}$. Primary lung alveolar cells were treated with $(B)$ control adenovirus or with $(C)$ adenovirus encoding short hairpin RNA targeting plectin expression, plated on a micropatterned surface comprising a series of matrix-coated circles, as detailed elsewhere (Eisenberg et al. 2013), and then costained for the FA protein talin (red) and the intermediate filament protein keratin (green). Bar, $20 \mu \mathrm{m}$ (panel 3). Note how knockdown of plectin not only inhibits the assembly of the perinuclear FAs but appears to "release" the keratin cytoskeleton, which then makes contact with FAs at the cell periphery. The boxed areas in the third panels in $B$ and $C$ are shown at higher power in the fourth panel (scale bar, $10 \mu \mathrm{m}$ ).

tin undergo an epithelial-mesenchymal transition in vitro that is accompanied by an increase in FA dynamics (Mendez et al. 2010). Further evidence for the importance of vimentin in FA structure and/or function comes from studies of "endoplasmic spreading" in mouse embryonic fibroblasts. For the cells to spread properly, they require both mature FAs and an intact vimentin network (Lynch et al. 2011). If polymerization of vimentin IFs is inhibited, the endoplasm is unable to spread and FAs appear smaller (Lynch et al. 2011). In addition, vimentin filament formation itself is not sufficient to restore a normal phenotype, but rather the vimentin IFs must extend into and contact FAs to generate a fully spread endoplasm (Lynch et al. 2013).

The importance of vimentin linkage to the functioning of FAs is underscored by recent results that indicate that the loss of IF-FA interaction impacts the ability of integrins to transduce mechanosignals, leading to activation of focal adhesion kinase (FAK) (Gregor et al. 2014). Specifically, when vimentin is unable to anchor to FAs, tension is lost throughout the cytoskeleton, impacting the ability of the cell to sense tension (Gregor et al. 2014). This leads to diminished FA dynamics and reduced migration, the latter 
being consistent with the reduced adhesion following vimentin knockdown reported by Bhattacharya and colleagues (Bhattacharya et al. 2009). The reduced adhesion is expected to affect the generation of traction forces necessary for migration (Gregor et al. 2014).

Additional evidence that vimentin regulates FA functions comes from analyses of lung cancer cells, in which it is reported that the guanine nucleotide exchange factor VAV2 not only localizes to vimentin-positive FAs but also complexes with both vimentin and FAK. Loss of vimentin inhibits FAK and VAV2 activity, as well as Rac1, the target of VAV2, resulting in defects in cell adhesion and motility (Havel et al. 2015).

The functional implications for keratin-FA association are less clear. Keratin might stabilize FAs such that they provide a more stable anchorage to the matrix, in much the same way that keratin-HD interaction stabilizes interactions between epithelial cells and the ECM.

\section{INTERACTIONS BETWEEN IFs AND DYSTROGLYCAN IN MUSCLE, NERVE, AND EPITHELIAL CELLS}

In striated muscles, the costamere is a structure linking the Z-line through the sarcolemma to the ECM, which relays lateral forces and signals. Moreover, it serves as a site of surface interaction of desmin, the major IF protein in muscles, and several other IF proteins, including synemin, paranemin, syncoilin, nestin, vimentin, keratin 8, and keratin 19 (Paulin and Li 2004; Capetanaki et al. 2007). As is the case with HDs and FAs, plectin mediates anchorage of IFs in muscle cells by binding to one or more components of the dystrophin-glycoprotein complex. The latter contain the plectin-binding proteins $\alpha$-dystrobrevin and DG (Hijikata et al. 2003; Rezniczek et al. 2007). Recently, the plakin domain of plectin has been shown to interact directly with DG to mediate interactions between desmin and the cell surface (Rezniczek et al. 2007; Favre et al. 2011; Peter et al. 2011). Interestingly, as is the case in muscle, a plectinDG complex tethers IFs to the surface of Schwann cells, the support cells of the peripheral nervous system, and provides a structural link from the IF cytoskeleton to laminins containing an $\alpha 2$ subunit in the ECM (Saito et al. 2003; Castañón et al. 2013). Furthermore, plectin also interacts with DG localized to Cajal bands in the abaxonal Schwann cell membrane and anchors vimentin IFs to the cell surface (Walko et al. 2013).

In addition to muscle and Schwann cells, DG is expressed in a variety of epithelial cells, including those that cover the inner surface of the alveoli of the lung. Indeed, in primary rat and mouse lung alveolar cells, DG is a component of a set of unique matrix adhesions arranged in a ring- like array toward the perinuclear zone (Eisenberg et al. 2013). These matrix adhesions not only contain typical FA components such as paxillin, vinculin, and talin, but also possess plectin and DG (Fig. 6B) (Eisenberg et al. 2013). Moreover, they are associated with, and appear to constrain, the organization of the keratin IF cytoskeleton of the cell (Fig. 6B) (Eisenberg et al. 2013). Intriguingly, plectin is not found in the FAs toward the cell periphery of these cells, and these FAs fail to interact with IFs. However, knockdown of plectin not only inhibits the assembly of these perinuclear FAs but appears to "release" the keratin cytoskeleton, which then makes contact with FAs at the cell periphery (Fig. 6C) (Eisenberg et al. 2013).

\subsection{Functions of IF-Associated Dystroglycan}

When plectin expression is lost in muscle, the desmin IF cytoskeleton fails to interact with DG at the cell surface with concomitant deterioration of the contractile apparatus and costameric integrity (Konieczny et al. 2008). Moreover, the relationship between the desmin IF network and plectin is highlighted by the similarity seen in the muscle phenotypes of desmin- and plectin-deficient mice, although loss of plectin generally produces a more severe phenotype (Wiche and Winter 2011). Indeed, humans diagnosed with defects in plectin expression display not only epithelial blistering but also muscular dystrophy (Smith et al. 1996).

Disruption of the IF-plectin-DG complex at the cell surface of myelinating Schwann cells results in myelin sheath deformations during aging. In addition, loss of DG leads not only to abnormalities in the myelin sheath but also to loss of sodium channels at nodes of Ranvier (Saito et al. 2003). Interestingly, DG appears to cooperate with $\alpha 6 \beta 4$ integrin in stabilizing myelin, and its loss leads to an age-dependent demyelination, although whether this involves IFs is unclear. In lung alveolar cells, both DG and plectin are involved in the transmission of mechanosignals that activate the extracellular-signal-regulated kinases ERK1/2 and 5'-adenosine monophosphate-activated kinase (AMPK) pathways (Jones et al. 2005; Budinger et al. 2008). The role of IFs in such mechanosignals is not clear. However, it is tempting to speculate that the keratin association of the DG/plectin-rich FAs in lung epithelial cells enhances their stability, facilitates their ability to undertake mechanosignaling, and might also help the cells to withstand the stretching and compressive forces to which they are subject in the intact lung.

\section{CONCLUSION}

IFs play important roles in stabilizing cell-cell and cellmatrix adhesions and, thereby, contribute to the mechan- 
ical and structural integrity of tissue. However, there are emerging data indicating that interactions between IFs and cell-surface proteins regulate other aspects of cell and tissue organization and behavior. For example, mice engineered to lack the entire keratin family die in utero. This is not solely because of the roles played by IFs in supporting cell integrity. Instead, the mice die from stunted growth attributed to a defect in glucose transport (Vijayaraj et al. 2009). Specifically, the mice fail to localize the glucose transporters GLUT1 and GLUT3 to the yolk sac apical membrane. In humans, surface expression of the cystic fibrosis transmembrane conductance regulator (CFTR), an anion channel and causative factor in cystic fibrosis, depends on an interaction with keratin-18 (Duan et al. 2012). Likewise, recruitment of cytosolic nucleotide-binding oligomerization domain-containing protein 2 (NOD2) to the plasma membrane depends on an interaction with vimentin, and might contribute to the pathogenesis of Crohn's disease (Stevens et al. 2013). Other curious examples from the cancer literature describe IF expression on the extracellular surface affecting such processes as plasmin-mediated matrix degradation (Pall et al. 2011; Kuchma et al. 2012). These developing stories indicate that, although the core function of IFs is clearly mechanical support, IFs modulate cell signaling and cell phenotype through their interactions with a variety of plasma membrane proteins and complexes.

\section{ACKNOWLEDGMENTS}

The Jones laboratory is supported by the National Institute of Arthritis and Musculoskeletal and Skin Diseases and the National Heart, Lung, and Blood Institute of the National Institutes of Health under Award Numbers RO1 AR054184 and RO1 HL092963. The Green laboratory is supported by the National Institutes of Health under Award Numbers RO1 AR041836, R37 AR43380, RO1 CA122151, a Leducq Transatlantic Network Grant, and the Joseph L. Mayberry endowment. The content of this article is solely the responsibility of the authors and does not necessarily represent the official views of the National Institutes of Health. We thank David Kelsell, John McGrath, James McMillan, and Cristina Basso for graciously allowing us to use their data in figures presented in this review.

\section{REFERENCES}

\section{* Reference is also in this collection.}

Abercrombie M, Heaysman JEM, Pegrum SM. 1971. The locomotion of fibroblasts in culture: IV. Electron microscopy of the leading lamella. Exp Cell Res 7: 359-367.

Acehan D, Petzold C, Gumper I, Sabatini DD, Muller EJ, Cowin P, Stokes DL. 2008. Plakoglobin is required for effective intermediate filament anchorage to desmosomes. J Invest Dermatol 128: 2665-2675.
Akiyama M, Takizawa Y, Sawamura D, Matsuo I, Shimizu H. 2003. Disruption of the suprabasal keratin network by mutation M150 T in the helix initiation motif of keratin 10 does not affect cornified cell envelope formation in human epidermis. Exp Dermatol 12: 638-645.

Albrecht LV, Zhang L, Shabanowitz J, Purevjav E, Towbin JA, Hunt DF, Green KJ. 2015. GSK3- and PRMT-1 dependent modifications of desmoplakin control desmoplakin-cytoskeleton dynamics. J Cell Biol 208: 597-612.

Al-Jassar C, Bikker H, Overduin M, Chidgey M. 2013. Mechanistic basis of desmosome-targeted diseases. J Mol Biol 425: 4006-4022.

* Bachir AI, Horwitz AR, Nelson WJ, Bianchini JM. 2016. Actin-based adhesion modules mediate cell interactions with the extracellular matrix and neighboring cells. Cold Spring Harb Perspect Biol doi: 101101/ cshperspect.a023234.

Barry AK, Tabdili H, Muhamed I, Wu J, Shashikanth N, Gomez GA, Yap AS, Gottardi CJ, de Rooij J, Wang N, et al. 2014. $\alpha$-Catenin cytomechanics: Role in cadherin-dependent adhesion and mechanotransduction. J Cell Sci 127: 1779-1791.

Bass-Zubek AE, Hobbs RP, Amargo EV, Garcia NJ, Hsieh SN, Chen X, Wahl JK 3rd, Denning MF, Green KJ. 2008. Plakophilin 2: A critical scaffold for PKC $\alpha$ that regulates intercellular junction assembly. J Cell Biol 181: 605-613.

Bershadsky AD, Tint IS, Svitkina TM. 1987. Association of intermediate filaments with vinculin-containing adhesion plaques of fibroblasts. Cell Motil Cytoskeleton 8: 274-283.

Bhattacharya R, Gonzalez AM, DeBiase PJ, Trejo HE, Goldman RD, Flitney FW, Jones JCR. 2009. Recruitment of vimentin to the cell surface by $\beta 3$ integrin and plectin mediates adhesion strength. J Cell Sci 122: $1390-1400$.

Bonne S, Gilbert B, Hatzfeld M, Chen X, Green KJ, van Roy F. 2003. Defining desmosomal plakophilin-3 interactions. J Cell Biol 161: 403-416.

Borradori L, Sonnenberg A. 1996. Hemidesmosomes: Roles in adhesion, signaling and human diseases. Cur Opin Cell Biol 8: 647-656.

Borradori L, Sonnenberg A. 1999. Structure and function of hemidesmosomes: More than simple adhesion complexes. J Invest Dermatol 112: $411-418$.

Borrmann CM, Grund C, Kuhn C, Hofmann I, Pieperhoff S, Franke WW. 2006. The area composita of adhering junctions connecting heart muscle cells of vertebrates. II. Colocalizations of desmosomal and fascia adhaerens molecules in the intercalated disk. Eur J Cell Biol 85: $469-485$.

Bouameur J-E, Schneider Y, Begré N, Hobbs RP, Lingasamy P, Fontao L, Green KJ, Favre B, Borradori L. 2013. Phosphorylation of serine 4642 in the C-terminus of plectin by MNK2 and PKA modulates its interaction with intermediate filaments. J Cell Sci 126: 4195-4207.

Brodehl A, Dieding M, Klauke B, Dec E, Madaan S, Huang T, Gargus J, Fatima A, Saric T, Cakar H, et al. 2013. The novel desmin mutant p.A120D impairs filament formation, prevents intercalated disk localization, and causes sudden cardiac death. Circ Cardio Gen 6: 615-623.

Budinger GRS, Urich D, DeBiase PJ, Chiarella SE, Burgess ZO, Baker CM, Soberanes S, Mutlu GM, Jones JCR. 2008. Stretch-induced activation of AMP kinase in the lung requires dystroglycan. Am J Resp Cell Mol Biol 39: 666-672.

Burgstaller G, Gregor M, Winter L, Wiche G. 2010. Keeping the vimentin network under control: Cell-matrix adhesion-associated plectin $1 \mathrm{f}$ affects cell shape and polarity of fibroblasts. Mol Biol Cell 21: 33623375.

Capetanaki Y, Bloch RJ, Kouloumenta A, Mavroidis M, Psarras S. 2007. Muscle intermediate filaments and their links to membranes and membranous organelles. Exp Cell Res 313: 2063-2076.

Castañón M, Walko G, Winter L, Wiche G. 2013. Plectin-intermediate filament partnership in skin, skeletal muscle, and peripheral nerve. Histochem Cell Biol 140: 33-53.

Chen X, Bonne S, Hatzfeld M, van Roy F, Green KJ. 2002. Protein binding and functional characterization of plakophilin 2. Evidence for its di- 
verse roles in desmosomes and $\beta$-catenin signaling. J Biol Chem 277: $10512-10522$.

Chitaev NA, Troyanovsky SM. 1997. Direct $\mathrm{Ca}^{+}{ }^{+}$-dependent heterophilic interaction between desmosomal cadherins, desmoglein and desmocollin, contributes to cell-cell adhesion. J Celll Biol 138: 193201.

Chung BM, Rotty JD, Coulombe PA. 2013. Networking galore: Intermediate filaments and cell migration. Curr Opin Cell Biol 25: 600-612.

Cukierman E, Pankov R, Yamada KM. 2002. Cell interactions with threedimensional matrices. Curr Opin Cell Biol 14: 633-640.

de Pereda JM, Ortega E, Alonso-Garcia N, Gomez-Hernandez M, Sonnenberg A. 2009. Advances and perspectives of the architecture of hemidesmosomes: Lessons from structural biology. Cell Adh Migr 3: 361-364.

Duan Y, Sun Y, Zhang F, Zhang WK, Wang D, Wang Y, Cao X, Hu W, Xie C, Cuppoletti J, et al. 2012. Keratin K18 increases cystic fibrosis transmembrane conductance regulator (CFTR) surface expression by binding to its C-terminal hydrophobic patch. J Biol Chem 287: 4054740559.

Dusek RL, Godsel LM, Green KJ. 2007. Discriminating roles of desmosomal cadherins: Beyond desmosomal adhesion. J Dermatol Sci 45: 7-21.

Eckes B, Dogic D, Colucci-Guyon E, Wang N, Maniotis A, Ingber D, Merckling A, Langa F, Aumailley M, Delouvee A, et al. 1998. Impaired mechanical stability, migration and contractile capacity in vimentindeficient fibroblasts. J Cell Sci 111: 1897-1907.

Eckes B, Colucci-Guyon E, Smola H, Nodder S, Babinet C, Krieg T, Martin P. 2000. Impaired wound healing in embryonic and adult mice lacking vimentin. J Cell Sci 113: 2455-2462.

Eisenberg JL, Beaumont KG, Takawira D, Hopkinson SB, Mrksich M, Budinger GRS, Jones JCR. 2013. Plectin-containing, centrally localized focal adhesions exert traction forces in primary lung epithelial cells. J Cell Sci 126: 3746-3755.

Esue O, Carson AA, Tseng Y, Wirtz D. 2006. diA direct interaction between actin and vimentinf filaments mediated by the tail domain of vimentin. J Biol Chem 281: 30393-30399.

Favre B, Schneider Y, Lingasamy P, Bouameur J-E, Begré N, Gontier Y, Steiner-Champliaud M-F, Frias MA, Borradori L, Fontao L. 2011. Plectin interacts with the rod domain of type III intermediate filament proteins desmin and vimentin. Eur J Cell Biol 90: 390-400.

Fine J-D. 2007. Epidermolysis bullosa: A genetic disease of altered cell adhesion and wound healing, and the possible clinical utility of topically applied thymosin $\beta 4 \beta 4$. Ann New York Acad Sci 1112: 396-406.

Foisner R, Leichtfried FE, Herrmann H, Small JV, Lawson D, Wiche G. 1988. Cytoskeleton-associated plectin: In situ localization, in vitro reconstitution, and binding to immobilized intermediate filament proteins. J Cell Biol 106: 723-733.

Fontao L, Stutzmann J, Gendry P, Launay JF. 1999. Regulation of the type II hemidesmosomal plaque assembly in intestinal epithelial cells. Exp Cell Res 250: 298-312.

Fontao L, Favre B, Riou S, Geerts D, Jaunin F, Saurat J-H, Green KJ, Sonnenberg A, Borradori L. 2003. Interaction of the bullous pemphigoid antigen 1 (BP230) and desmoplakin with intermediate filaments is mediated by distinct sequences within their $\mathrm{COOH}$ terminus. $\mathrm{Mol}$ Biol Cell 14: 1978-1992.

Galbraith CG, Yamada KM, Sheetz MP. 2002. The relationship between force and focal complex development. J Cell Biol 159: 695-705.

Gallicano GI, Bauer C, Fuchs E. 2001. Rescuing desmoplakin function in extra-embryonic ectoderm reveals the importance of this protein in embryonic heart, neuroepithelium, skin and vasculature. Development 128: 929-941.

Garcia-Gras E, Lombardi R, Giocondo MJ, Willerson JT, Schneider MD, Khoury DS, Marian AJ. 2006. Suppression of canonical Wnt/ $\beta$-catenin signaling by nuclear plakoglobin recapitulates phenotype of arrhythmogenic right ventricular cardiomyopathy. J Clin Invest 116: 2012-2021.
Garrod D, Chidgey M. 2008. Desmosome structure, composition and function. Biochim Biophys Acta 1778: 572-587.

Garrod D, Kimura TE. 2008. Hyper-adhesion: A new concept in cell-cell adhesion. Biochem Soc Trans 36: 195-201.

Garrod DR, Berika MY, Bardsley WF, Holmes D, Tabernero L. 2005. Hyper-adhesion in desmosomes: Its regulation in wound healing and possible relationship to cadherin crystal structure. J Cell Sci 118: 5743-5754.

Geiger B, Bershadsky A, Pankov R, Yamada KM. 2001. Transmembrane crosstalk between the extracellular matrix and the cytoskeleton. Nat Rev Mol Cell Biol 2: 793-805.

Geiger B, Spatz JP, Bershadsky AD. 2009. Environmental sensing through focal adhesions. Nat Rev Mol Cell Biol 10: 21-33.

Getsios S, Amargo EV, Dusek RL, Ishii K, Sheu L, Godsel LM, Green KJ. 2004. Coordinated expression of desmoglein 1 and desmocollin 1 regulates intercellular adhesion. Differentiation 72: 419-433.

Getsios S, Simpson CL, Kojima S, Harmon R, Sheu LJ, Dusek RL, Cornwell M, Green KJ. 2009. Desmoglein 1-dependent supression of EGFR signaling promotes epidermal differentiation and morphogenesis. J Cell Biol 185: 1243-1258.

Godsel LM, Hsieh SN, Amargo EV, Bass AE, Pascoe-McGillicuddy LT, Huen AC, Thorne ME, Gaudry CA, Park JK, Myung K, et al. 2005. Desmoplakin assembly dynamics in four dimensions: Multiple phases differentially regulated by intermediate filaments and actin. J Cell Biol 171: 1045-1059.

Godsel LM, Dubash AD, Bass-Zubek AE, Amargo EV, Klessner JL, Hobbs RP, Chen X, Green KJ. 2010. Plakophilin 2 couples actomyosin remodeling to desmosomal plaque assembly via RhoA. Mol Biol Cell 21: 2844-2859.

Gonzales M, Weksler B, Tsuruta D, Goldman RD, Yoon KJ, Hopkinson SB, Flitney FW, Jones JCR. 2001. Structure and function of a vimentinassociated matrix adhesion in endothelial cells. Mol Biol Cell 12: 85100.

Goossens S, Janssens B, Bonné S, De Rycke R, Braet F, van Hengel J, van Roy F. 2007. A unique and specific interaction between $\alpha$ T-catenin and plakophilin-2 in the area composita, the mixed-type junctional structure of cardiac intercalated discs. J Cell Sci 120: 2126-2136.

Green KJ, Gaudry CA. 2000. Are desmosomes more than tethers for intermediate filaments? Nat Rev Mol Cell Biol 3: 208-216.

Green KJ, Jones JC. 1996. Desmosomes and hemidesmosomes: Structure and function of molecular components. FASEB J 10: 871-881.

Gregor M, Osmanagic-Myers S, Burgstaller G, Wolfram M, Fischer I, Walko G, Resch GP, Jörgl A, Herrmann H, Wiche G. 2014. Mechanosensing through focal adhesion-anchored intermediate filaments. FASEB J 28: 715-729.

Grossmann KS, Grund C, Huelsken J, Behrend M, Erdmann B, Franke WW, Birchmeier W. 2004. Requirement of plakophilin 2 for heart morphogenesis and cardiac junction formation. J Cell Biol 167: $149-160$.

Groves RW, Liu L, Dopping-Hepenstal PJ, Markus HS, Lovell PA, Ozoemena L, Lai-Cheong JE, Gawler J, Owaribe K, Hashimoto T, et al. 2010. A homozygous nonsense mutation within the dystonin gene coding for the coiled-coil domain of the epithelial isoform of BPAG1 underlies a new subtype of autosomal recessive epidermolysis bullosa simplex. J Invest Dermatol 130: 1551-1557.

Guo L, Degenstein L, Dowling J, Yu Q-C, Wollmann R, Perman B, Fuchs E. 1995. Gene targeting of BPAG1: Abnormalities in mechanical strength and cell migration in stratified epithelia and neurologic degeneration. Cell 81: 233-243.

Hamill KJ, Hopkinson SB, DeBiase P, Jones JCR. 2009. BPAGle maintains keratinocyte polarity through $\beta 4$ integrin-mediated modulation of Rac 1 and cofilin activities. Mol Biol Cell 20: 2954-2962.

Harmon RM, Green KJ. 2013. Structural and functional diversity of desmosomes. Cell Commun Adhes 20: 171-187.

Harmon RM, Simpson CL, Johnson JL, Koetsier JL, Dubash AD, Najor NA, Sarig O, Sprecher E, Green KJ. 2013. Desmoglein-1/Erbin inter- 
action suppresses ERK activation to support epidermal differentiation. J Clin Invest 123: 1556-1570.

Hatzfeld M, Wolf A, Keil R. 2014. Plakophilins in desmosomal adhesion and signaling. Cell Commun Adhes 21: 25-42.

Havel LS, Kline ER, Salgueiro AM, Marcus AI. 2015. Vimentin regulates lung cancer cell adhesion through a VAV2-Racl pathway to control focal adhesion kinase activity. Oncogene 34: 1979-1990.

Herrmann H, Strelkov SV, Burkhard P, Aebi U. 2009. Intermediate filaments: Primary determinants of cell architecture and plasticity. J Invest Dermatol 119: 1772-1783.

Hijikata T, Murakami T, Ishikawa H, Yorifuji H. 2003. Plectin tethers desmin intermediate filaments onto subsarcolemmal dense plaques containing dystrophin and vinculin. Histochem Cell Biol 119: 109123.

Hobbs RP, Amargo EV, Somasundaram A, Simpson CL, Prakriya M, Denning MF, Green KJ. 2011. The calcium ATPase SERCA2 regulates desmoplakin dynamics and intercellular adhesive strength through modulation of PKC $\alpha$ signaling. FASEB J 25: 990-1001.

Hofmann I, Mertens C, Brettel M, Nimmrich V, Schnolzer M, Herrmann H. 2000. Interaction of plakophilins with desmoplakin and intermediate filament proteins: An in vitro analysis. J Cell Sci 113: $2471-2483$.

Hopkinson SB, Jones JCR. 2000. The N terminus of the transmembrane protein BP180 interacts with the $\mathrm{N}$-terminal domain of BP230, thereby mediating keratin cytoskeleton anchorage to the cell surface at the site of the hemidesmosome. Mol Biol Cell 11: 277-286.

Hopkinson SB, Baker SE, Jones JC. 1995. Molecular genetic studies of a human epidermal autoantigen (the $180-\mathrm{kD}$ bullous pemphigoid antigen/BP180): Identification of functionally important sequences within the BP180 molecule and evidence for an interaction between BP180 and $\alpha 6$ integrin. J Cell Biol 130: 117-125.

Huen AC, Park JK, Godsel LM, Chen X, Bannon LJ, Amargo EV, Hudson TY, Mongiu AK, Leigh IM, Kelsell DP, et al. 2002. Intermediate filament-membrane attachments function synergistically with actin-dependent contacts to regulate intercellular adhesive strength. J Cell Biol 159: 1005-1017.

* Jacob JT, Coulombe PA, Kwan R, Omary MB. 2016. Types I and II keratin intermediate filaments. Cold Spring Harb Perspect Biol doi: 101101/ cshperspect.a018275.

Jefferson JJ, Leung CL, Liem RK. 2004. Plakins: Goliaths that link cell junctions and the cytoskeleton. Nat Rev Mol Cell Biol 5: 542-553.

Jefferson JJ, Ciatto C, Shapiro L, Liem RKH. 2007. Structural analysis of the plakin domain of bullous pemphigoid antigen 1 (BPAG1) suggests that plakins are members of the spectrin superfamily. J Mol Biol 366: $244-257$

Jones JC, Goldman RD. 1985. Intermediate filaments and the initiation of desmosome assembly. J Cell Biol 101: 506-517.

Jones JC, Hopkinson SB, Goldfinger LE. 1998. Structure and assembly of hemidesmosomes. Bioessays 20: 488-494.

Jones JCR, Lane K, Hopkinson SB, Lecuona E, Geiger RC, Dean DA, Correa-Meyer E, Gonzales M, Campbell K, Sznajder JI, et al. 2005. Laminin-6 assembles into multimolecular fibrillar complexes with perlecan and participates in mechanical-signal transduction via a dystroglycan-dependent, integrin-independent mechanism. J Cell Sci 118: $2557-2566$.

Katz B-Z, Zamir E, Bershadsky A, Kam Z, Yamada KM, Geiger B. 2000. Physical state of the extracellular matrix regulates the structure and molecular composition of cell-matrix adhesions. Mol Biol Cell 11: 1047-1060.

Klatte DH, Jones JC. 1994. Purification of the 230-kD bullous pemphigoid antigen (BP230) from bovine tongue mucosa: Structural analyses and assessment of BP230 tissue distribution using a new monoclonal antibody. J Invest Dermatol 102: 39-44.

Konieczny P, Fuchs P, Reipert S, Kunz WS, Zeöld A, Fischer I, Paulin D, Schröder R, Wiche G. 2008. Myofiber integrity depends on desmin network targeting to Z-disks and costameres via distinct plectin isoforms. J Cell Biol 181: 667-681.
Kostan J, Gregor M, Walko G, Wiche G. 2009. Plectin isoform-dependent regulation of k-integrin $\alpha 6 \beta 4$ anchorage via $\mathrm{Ca}^{+} /$calmodulin. J Biol Chem 284: 18525-18536.

Koster J, Geerts D, Favre B, Borradori L, Sonnenberg A. 2003. Analysis of the interactions between BP180, BP230, plectin and the integrin

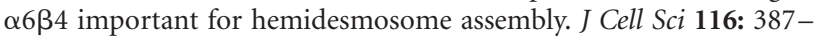
399.

Kouklis PD, Hutton E, Fuchs E. 1994. Making a connection: Direct binding between keratin intermediate filaments and desmosomal proteins. J Cell Biol 127: 1049-1060.

Kowalczyk AP, Green KJ. 2013. Structure, function, and regulation of desmosomes. Prog Mol Biol Transl Sci 116: 95-118.

Kowalczyk AP, Stappenbeck TS, Parry DAD, Palka HL, Virata MLA, Bornslaeger EA, Nilles LA, Green KJ. 1994. Structure and function of desmosomal transmembrane core and plaque molecules. Biophys Chem 50: $97-112$

Kowalczyk AP, Bornslaeger EA, Borgwardt JE, Palka HL, Dhaliwal AS, Corcoran CM, Denning MF, Green KJ. 1997. The amino-terminal domain of desmoplakin binds to plakoglobin and clusters desmosomal cadherin-plakoglobin complexes. J Cell Biol 139: 773-784.

Kowalczyk AP, Hatzfeld M, Bornslaeger EA, Kopp DS, Borgwardt JE, Corcoran CM, Settler A, Green KJ. 1999. The head domain of plakophilin-1 binds to desmoplakin and enhances its recruitment to desmosomes. Implications for cutaneous disease. J Biol Chem 274: $18145-18148$.

Kreis S, Schönfeld H-J, Melchior C, Steiner B, Kieffer N. 2005. The intermediate filament protein vimentin binds specifically to a recombinant integrin $\alpha 2 / \beta 1$ cytoplasmic tail complex and co-localizes with native $\alpha 2 / \beta 1$ in endothelial cell focal adhesions. Exp Cell Res 305: $110-121$

Kreplak L, Herrmann H, Aebi U. 2008. Tensile properties of single desmin intermediate filaments. Biophys J 94: 2790-2799.

Kroger C, Loschke F, Schwarz N, Windoffer R, Leube RE, Magin TM. 2013. Keratins control intercellular adhesion involving PKC- $\alpha$-mediated desmoplakin phosphorylation. J Cell Biol 201: 681-692.

Kuchma MH, Kim JH, Muller MT, Arlen PA. 2012. Prostate cancer cell surface-associated keratin 8 and its implications for enhanced plasmin activity. Protein J 31: 195-205.

Leitner A, Paust T, Marti O, Walther P, Herrmann H, Beil M. 2012. Properties of intermediate filament networks assembled from keratin 8 and 18 in the presence of $\mathrm{Mg}(2)^{+}$. Biophys J 103: 195-201.

Leonard M, Chan Y, Menko AS. 2008. Identification of a novel intermediate filament-linked $\mathrm{N}$-cadherin $/ \boldsymbol{\gamma}$-catenin complex involved in the establishment of the cytoarchitecture of differentiated lens fiber cells. Dev Biol 319: 298-308.

* Liem RKH. 2016. Cytoskeletal integrators: The spectrin superfamily. Cold Spring Harb Perspect Biol 8: a018259.

Lo SH. 2006. Focal adhesions: What's new inside. Dev Biol 294: 280-291.

Lowndes M, Rakshit S, Shafraz O, Borghi N, Harmon R, Green K, Sivasankar S, Nelson WJ. 2014. Different roles of cadherins in the assembly and structural integrity of the desmosome complex. J Cell Sci 127: $2339-2350$

Lynch CD, Gauthier NC, Biais N, Lazar AM, Roca-Cusachs P, Yu C-H, Sheetz MP. 2011. Filamin depletion blocks endoplasmic spreading and destabilizes force-bearing adhesions. Mol Biol Cell 22: 1263-1273.

Lynch CD, Lazar AM, Iskratsch T, Zhang X, Sheetz MP. 2013. Endoplasmic spreading requires coalescence of vimentin intermediate filaments at force-bearing adhesions. Mol Biol Cell 24: 21-30.

Lyon RC, Mezzano V, Wright AT, Pfeiffer E, Chuang J, Banares K, Castaneda A, Ouyang K, Cui L, Contu R, et al. 2014. Connexin defects underlie arrhythmogenic right ventricular cardiomyopathy in a novel mouse model. Hum Mol Genet 23: 1134-1150.

Mainiero F, Murgia C, Wary KK, Curatola AM, Pepe A, Blumemberg M, Westwick JK, Der CJ, Giancotti FG. 1997. The coupling of $\alpha 6 \beta 4$ integrin to Ras-MAP kinase pathways mediated by Shc controls keratinocyte proliferation. EMBO J 16: 2365-2375. 
J.C.R. Jones et al.

Mendez MG, Kojima S-I, Goldman RD. 2010. Vimentin induces changes in cell shape, motility, and adhesion during the epithelial to mesenchymal transition. FASEB J 24: 1838-1851.

Meng JJ, Bornslaeger EA, Green KJ, Steinert PM, Ip W. 1997. Two-hybrid analysis reveals fundamental differences in direct interactions between desmoplakin and cell type-specific intermediate filaments. J Biol Chem 272: 21495-21503.

Mercurio AM, Rabinovitz I, Shaw LM. 2001. The $\alpha 6 \beta 4$ integrin and epithelial cell migration. Curr Opin Cell Biol 13: 541-545.

Nekrasova OE, Amargo EV, Smith WO, Chen J, Kreitzer GE, Green KJ. 2011. Desmosomal cadherins utilize distinct kinesins for assembly into desmosomes. J Cell Biol 195: 1185-1203.

Nie Z, Merritt A, Rouhi-Parkouhi M, Tabernero L, Garrod D. 2011. Membrane-impermeable cross-linking provides evidence for homophilic, isoform-specific binding of desmosomal cadherins in epithelial cells. J Biol Chem 286: 2143-2154.

Norgett EE, Hatsell SJ, Carvajal-Huerta L, Cabezas JC, Common J, Purkis PE, Whittock N, Leigh IM, Stevens HP, Kelsell DP. 2000. Recessive mutation in desmoplakin disrupts desmoplakin-intermediate filament interactions and causes dilated cardiomyopathy, woolly hair and keratoderma. Hum Mol Genet 9: 2761-2766.

North AJ, Bardsley WG, Hyam J, Bornslaeger EA, Cordingley HC, Trinnaman B, Hatzfeld M, Green KJ, Magee AI, Garrod DR. 1999. Molecular map of the desmosomal plaque. J Cell Sci 112: $4325-4336$.

Pall T, Pink A, Kasak L, Turkina M, Anderson W, Valkna A, Kogerman P. 2011. Soluble CD44 interacts with intermediate filament protein vimentin on endothelial cell surface. PLoS ONE 6: e29305.

Pasdar M, Krzeminski KA, Nelson WJ. 1991. Regulation of desmosome assembly in MDCK epithelial cells: Coordination of membrane core and cytoplasmic plaque domain assembly at the plasma membrane. J Cell Biol 113: 645-655.

Patel DM, Dubash AD, Kreitzer G, Green KJ. 2014. Disease mutations in desmoplakin inhibit Cx43 membrane targeting mediated by desmoplakin-EB1 interactions. J Cell Biol 206: 779-797.

Paulin D, Li Z. 2004. Desmin: A major intermediate filament protein essential for the structural integrity and function of muscle. Exp Cell Res 301: 1-7.

Peter AK, Cheng H, Ross RS, Knowlton KU, Chen J. 2011. The costamere bridges sarcomeres to the sarcolemma in striated muscle. Prog Ped Cardiol 31: 83-88.

Petrof G, Mellerio JE, McGrath JA. 2012. Desmosomal genodermatoses. Br J Dermatol 166: 36-45.

Rabinovitz I, Tsomo L, Mercurio AM. 2004. Protein kinase C- $\alpha$ phosphorylation of specific serines in the connecting segment of the $\beta 4$ integrin regulates the dynamics of type II hemidesmosomes. Mol Cell Biol 24: 4351-4360.

Rezniczek GA, Pereda JMd, Reipert S, Wiche G. 1998. Linking integrin $\alpha 6 \beta 4$-based cell adhesion to the intermediate filament cytoskeleton: Direct interaction between the $\beta 4$ subunit and plectin at multiple molecular sites. J Cell Biol 141: 209-225.

Rezniczek GA, Konieczny P, Nikolic B, Reipert S, Schneller D, Abrahamsberg C, Davies KE, Winder SJ, Wiche G. 2007. Plectin If scaffolding at the sarcolemma of dystrophic $(m d x)$ muscle fibers through multiple interactions with $\beta$-dystroglycan. J Cell Biol 176: 965-977.

Rizzo S, Pilichou K, Thiene G, Basso C. 2012. The changing spectrum of arrhythmogenic (right ventricular) cardiomyopathy. Cell Tissue Res 348: 319-323.

Saito F, Moore SA, Barresi R, Henry MD, Messing A, Ross-Barta SE, Cohn RD, Williamson RA, Sluka KA, Sherman DL, et al. 2003. Unique role of dystroglycan in peripheral nerve myelination, nodal structure, and sodium channel stabilization. Neuron 38: 747-758.

Schmelz M, Franke WW. 1993. Complexus adhaerentes, a new group of desmoplakin-containing junctions in endothelial cells: The syndesmos connecting retothelial cells of lymph nodes. Eur J Cell Biol 61: $274-289$.
Seltmann K, Roth W, Kroger C, Loschke F, Lederer M, Huttelmaier S, Magin TM. 2013. Keratins mediate localization of hemidesmosomes and repress cell motility. J Invest Dermatol 133: 181-190.

Seltmann K, Cheng F, Wiche G, Eriksson JE, Magin TM. 2015. Keratins stabilize hemidesmosomes through regulation of $\beta 4$-integrin turnover. J Invest Dermatol 135: 1609-1620.

Smith EA, Fuchs E. 1998. Defining the interactions between intermediate filaments and desmosomes. J Cell Biol 141: 1229-1241.

Smith FJD, Eady RAJ, Leigh IM, McMillan JR, Rugg EL, Kelsell DP, Bryant SP, Spurr NK, Geddes JF, Kirtschig G, et al. 1996. Plectin deficiency results in muscular dystrophy with epidermolysis bullosa. Nat Genet 13: 450-457.

Song S, Landsbury A, Dahm R, Liu Y, Zhang Q, Quinlan RA. 2009. Functions of the intermediate filament cytoskeleton in the eye lens. J Clin Invest 119: 1837-1848.

Spurny R, Gregor M, Castañón MJ, Wiche G. 2008. Plectin deficiency affects precursor formation and dynamics of vimentin networks. Exp Cell Res 314: 3570-3580.

Stappenbeck TS, Green KJ. 1992. The desmoplakin carboxyl terminus coaligns with and specifically disrupts intermediate filament networks when expressed in cultured cells. J Cell Biol 116: 1197-1209.

Stevens C, Henderson P, Nimmo ER, Soares DC, Dogan B, Simpson KW, Barrett JC, Wilson DC, Satsangi J. 2013. The intermediate filament protein, vimentin, is a regulator of NOD2 activity. Gut 62: 695-707.

Straub BK, Boda J, Kuhn C, Schnoelzer M, Korf U, Kempf T, Spring H, Hatzfeld M, Franke WW. 2003. A novel cell-cell junction system: The cortex adhaerens mosaic of lens fiber cells. J Cell Sci 116: 4985-4995.

Tsuruta D, Jones JCR. 2003. The vimentin cytoskeleton regulates focal contact size and adhesion of endothelial cells subjected to shear stress. J Cell Sci 116: 4977-4984.

Tsuruta D, Hopkinson SB, Lane KD, Werner ME, Cryns VL, Jones JCR. 2003. Crucial role of the specificity-determining loop of the integrin $\beta 4$ subunit in the binding of cells to laminin- 5 and outside-in signal transduction. J Biol Chem 278: 38707-38714.

Uitto J, Pulkkinen L, Smith FJD, McLean WHI. 1996. Plectin and human genetic disorders of the skin and muscle. Exp Dermatol 5: 237-246.

Van den Bergh F, Eliason SL, Giudice GJ. 2011. Type XVII collagen (BP180) can function as a cell-matrix adhesion molecule via binding to laminin 332. Matrix Biol 30: 100-108.

Vasioukhin V, Bowers E, Bauer C, Degenstein L, Fuchs E. 2001. Desmoplakin is essential in epidermal sheet formation. Nat Cell Biol 3: 10761085.

Vijayaraj P, Kroger C, Reuter U, Windoffer R, Leube RE, Magin TM. 2009. Keratins regulate protein biosynthesis through localization of GLUT1 and -3 upstream of AMP kinase and Raptor. J Cell Biol 187: 175-184.

Walko G, Wögenstein KL, Winter L, Fischer I, Feltri ML, Wiche G. 2013. Stabilization of the dystroglycan complex in Cajal bands of myelinating Schwann cells through plectin-mediated anchorage to vimentin filaments. Glia 61: 1274-1287.

Wallis S, Lloyd S, Wise I, Ireland G, Fleming TP, Garrod D. 2000. The $\alpha$ isoform of protein kinase $\mathrm{C}$ is involved in signaling the response of desmosomes to wounding in cultured epithelial cells. Mol Biol Cell 11: 1077-1092.

Watt FM, Mattey DL, Garrod DR. 1984. Calcium-induced reorganization of desmosomal components in cultured human keratinocytes. J Cell Biol 99: 2211-2215.

Weber GF, Bjerke MA, DeSimone DW. 2012. A mechanoresponsive cadherin-keratin complex directs polarized protrusive behavior and collective cell migration. Dev Cell 22: 104-115.

Wiche G, Baker MA. 1982. Cytoplasmic network arrays demonstrated by immunolocalization using antibodies to a high molecular weight protein present in cytoskeletal preparations from cultured cells. Exp Cell Res 138: 15-29.

Wiche G, Winter L. 2011. Plectin isoforms as organizers of intermediate filament cytoarchitecture. BioArch 1: 14-20. 
Wickstead B, Gull K. 2011. The evolution of the cytoskeleton. J Cell Biol 194: $513-525$.

Windoffer R, Borchert-Stuhltrager M, Leube RE. 2002. Desmosomes: Interconnected calcium-dependent structures of remarkable stability with significant integral membrane protein turnover. J Cell Sci 115: $1717-1732$.

Windoffer R, Kölsch A, Wöll S, Leube RE. 2006. Focal adhesions are hotspots for keratin filament precursor formation. J Cell Biol 173: 341-348.

Winter L, Wiche G. 2013. The many faces of plectin and plectinopathies: Pathology and mechanisms. Acta Neuropathol 125: 77-93.

Wozniak MA, Modzelewska K, Kwong L, Keely PJ. 2004. Focal adhesion regulation of cell behavior. Biochim Biophys Acta 1692: 103-119.
Yang Y, Dowling J, Yu Q-C, Kouklis P, Cleveland DW, Fuchs E. 1996. An essential cytoskeletal linker protein connecting actin microfilaments to intermediate filaments. Cell 86: 655-665.

Yoon KH, FitzGerald PG. 2009. Periplakin interactions with lens intermediate and beaded filaments. Invest Ophth Vis Sci 50: 12831289.

Zamir E, Geiger B. 2001. Molecular complexity and dynamics of cellmatrix adhesions. J Cell Sci 114: 3583-3590.

Zamir E, Katz BZ, Aota S, Yamada KM, Geiger B, Kam Z. 1999. Molecular diversity of cell-matrix adhesions. J Cell Sci 112: 1655-1669.

Ziaidel-Bar R, Cohen M, Addadi L, Geiger B. 2004. Hierarchical assembly of cell-matrix adhesion complexes. Biochem Soc Trans 32: 416420 . 


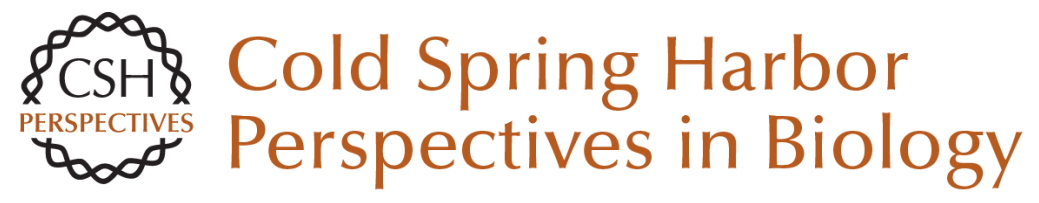

\section{Intermediate Filaments and the Plasma Membrane}

Jonathan C.R. Jones, Chen Yuan Kam, Robert M. Harmon, Alexandra V. Woychek, Susan B. Hopkinson and Kathleen J. Green

Cold Spring Harb Perspect Biol 2017; doi: 10.1101/cshperspect.a025866

Subject Collection The Cytoskeleton

Microtubules and Microtubule-Associated

Proteins

Holly V. Goodson and Erin M. Jonasson

Motor Proteins

H. Lee Sweeney and Erika L.F. Holzbaur

Myosin-Driven Intracellular Transport

Margaret A. Titus

The Actin Cytoskeleton and Actin-Based Motility Tatyana Svitkina

Mechanical Properties of the Cytoskeleton and Cells

Adrian F. Pegoraro, Paul Janmey and David A. Weitz

Intermediate Filaments and the Regulation of Cell Motility during Regeneration and Wound Healing Fang Cheng and John E. Eriksson

Intermediate Filaments and the Plasma Membrane Jonathan C.R. Jones, Chen Yuan Kam, Robert M. Harmon, et al.

\author{
Overview of the Cytoskeleton from an \\ Evolutionary Perspective \\ Thomas D. Pollard and Robert D. Goldman \\ Types I and II Keratin Intermediate Filaments \\ Justin T. Jacob, Pierre A. Coulombe, Raymond \\ Kwan, et al. \\ Muscle Contraction \\ H. Lee Sweeney and David W. Hammers \\ Type III Intermediate Filaments Desmin, Glial \\ Fibrillary Acidic Protein (GFAP), Vimentin, and \\ Peripherin \\ Elly M. Hol and Yassemi Capetanaki \\ Cytokinesis in Metazoa and Fungi \\ Michael Glotzer
}

Ciliary Motility: Regulation of Axonemal Dynein Motors

Rasagnya Viswanadha, Winfield S. Sale and Mary E. Porter

Actin-Based Adhesion Modules Mediate Cell Interactions with the Extracellular Matrix and Neighboring Cells Alexia I. Bachir, Alan Rick Horwitz, W. James Nelson, et al.

For additional articles in this collection, see http://cshperspectives.cshlp.org/cgi/collection/

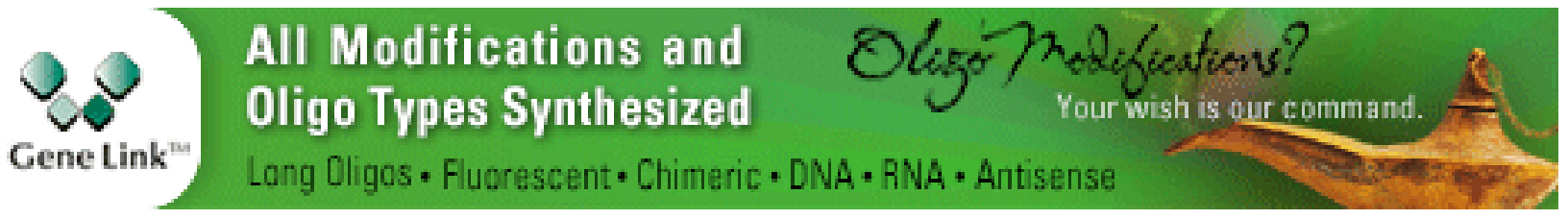

Copyright @ 2017 Cold Spring Harbor Laboratory Press; all rights reserved 
Intracellular Motility of Intermediate Filaments Rudolf E. Leube, Marcin Moch and Reinhard Windoffer
Microtubule-Based Transport and the Distribution, Tethering, and Organization of Organelles Kari Barlan and Vladimir I. Gelfand

For additional articles in this collection, see http://cshperspectives.cshlp.org/cgi/collection/

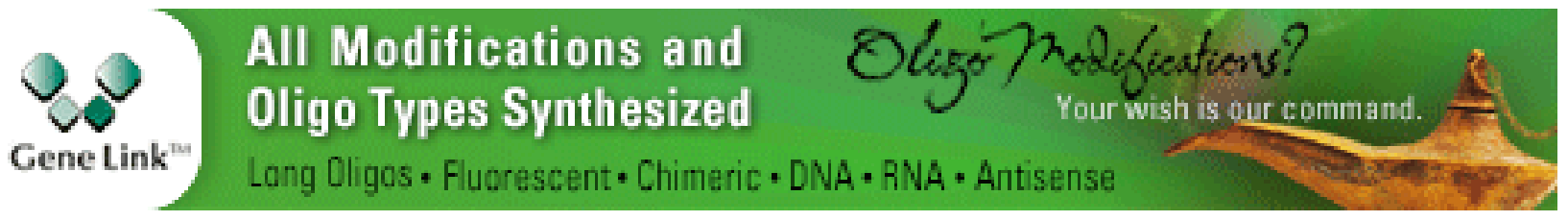

Copyright @ 2017 Cold Spring Harbor Laboratory Press; all rights reserved 